Portland State University

PDXScholar

TREC Final Reports

Transportation Research and Education Center

(TREC)

8-2021

\title{
Data-Driven Mobility Strategies for Multimodal Transportation
}

\author{
Yao-Jan Wu \\ University of Arizona \\ Xianfeng Terry Yang \\ University of Utah \\ Sirisha Kothuri \\ Portland State University, skothuri@pdx.edu \\ Abolfazl Karimpour \\ University of Arizona \\ Qinzheng Wang \\ University of Utah
}

See next page for additional authors

Follow this and additional works at: https://pdxscholar.library.pdx.edu/trec_reports

Part of the Transportation Commons, Urban Studies Commons, and the Urban Studies and Planning Commons

Let us know how access to this document benefits you.

\section{Recommended Citation}

Wu, Y., Yang, X., Kothuri, S., Karimpour, A., Wang, Q., Anderson, J. Data-Driven Mobility Strategies for Multimodal Transportation. NITC-RR-1298. Portland, OR: Transportation Research and Education Center (TREC), 2021. https://dx.doi.org/10.15760/trec.262

This Report is brought to you for free and open access. It has been accepted for inclusion in TREC Final Reports by an authorized administrator of PDXScholar. Please contact us if we can make this document more accessible: pdxscholar@pdx.edu. 


\section{Authors}

Yao-Jan Wu, Xianfeng Terry Yang, Sirisha Kothuri, Abolfazl Karimpour, Qinzheng Wang, and Jason Anderson 


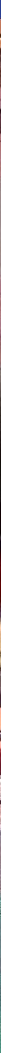

\title{
Data-Driven Mobility Strategies for Multimodal Transportation
}

\author{
Yao-Jan Wu, Ph.D. \\ Xianfeng (Terry) Yang, Ph.D. \\ Sirisha Kothuri, Ph.D \\ Abolfazl Karimpour, Ph.D. \\ Qinzheng Wang \\ Jason Anderson, Ph.D.
}

A]. OF ARIZONA.

UHE
OF IVERSITY
OF UTAH

胥 Portland $\underset{\cup N \text { StansIIY }}{\text { State }}$ 


\title{
Data-Driven Mobility Strategies for Multimodal Transportation
}

\author{
Final Report
}

NITC-RR-1298

by

Yao-Jan Wu, Ph.D., P.E., University of Arizona Xianfeng Terry Yang, Ph.D., University of Utah Sirisha Kothuri, Ph.D., Portland State University Abolfazl Karimpour, Ph.D., University of Arizona

Qinzheng Wang, University of Utah Jason Anderson, Ph.D., Portland State University

for

National Institute for Transportation and Communities (NITC)

P.O. Box 751

Portland, OR 97207
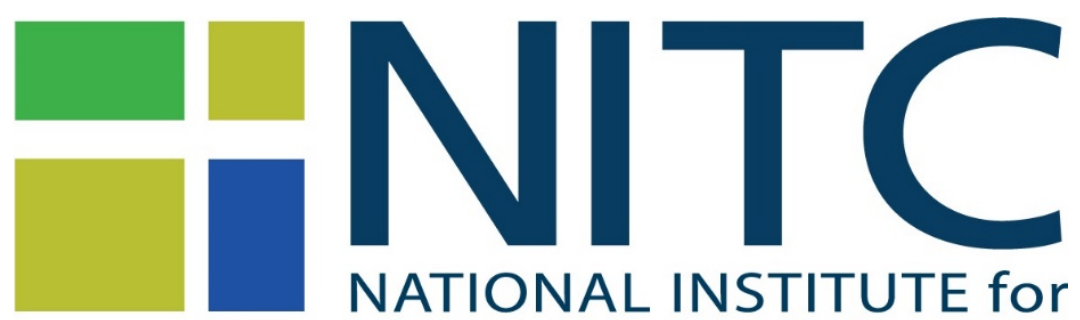

TRANSPORTATION and COMMUNITIES

August 2021 


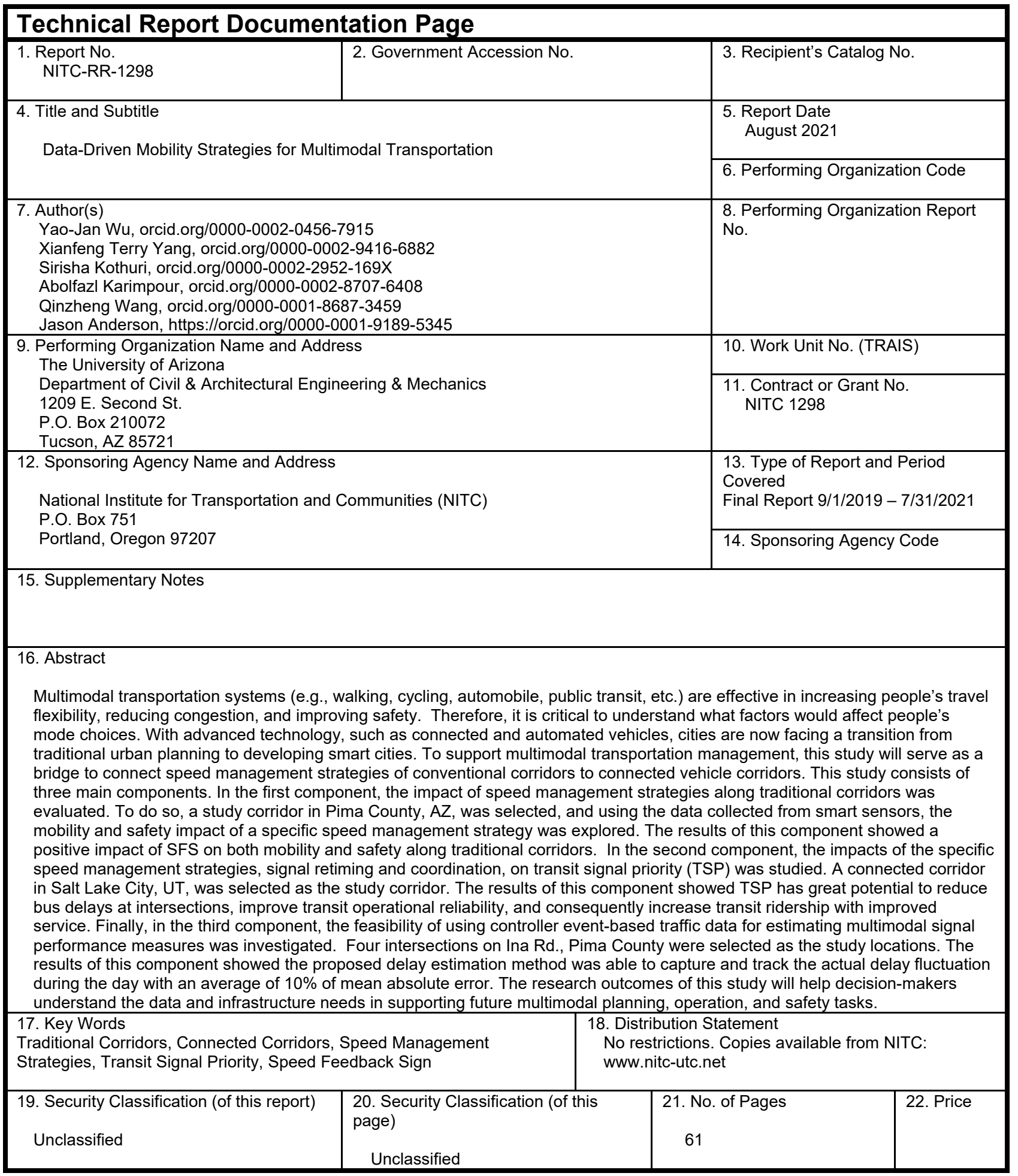




\section{ACKNOWLEDGEMENTS}

This study was funded by the National Institute for Transportation and Communities (NITC; grant number 1298) a U.S. DOT University Transportation Center. The authors would like to also thank the Pima County Department of Transportation (PCDOT) and the Utah Department of Transportation (UDOT) for funding and data support.

\section{DISCLAIMER}

The contents of this report reflect the views of the authors, who are solely responsible for the facts and the accuracy of the material and information presented herein. This document is disseminated under the sponsorship of the U.S. Department of Transportation University Transportation Centers Program in the interest of information exchange. The U.S. Government assumes no liability for the contents or use thereof. The contents do not necessarily reflect the official views of the U.S. Government. This report does not constitute a standard, specification, or regulation.

\section{RECOMMENDED CITATION}

Wu, Y., Yang, X., Kothuri, S., Karimpour, A., Wang, Q., Anderson, J. Data-Driven Mobility Strategies for Multimodal Transportation. NITC-RR-1298. Portland, OR: Transportation Research and Education Center (TREC), 2021. 


\section{TABLE OF CONTENTS}

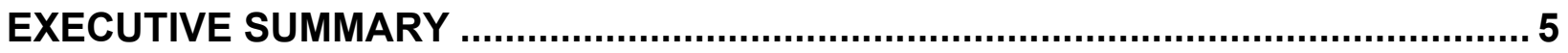

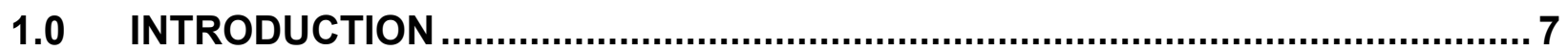

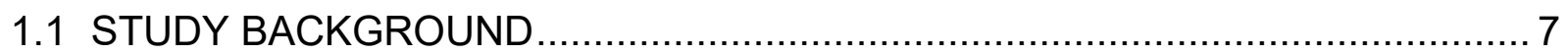

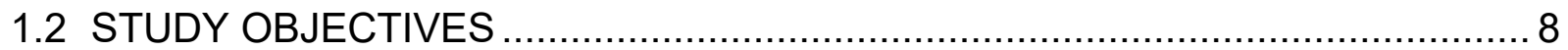

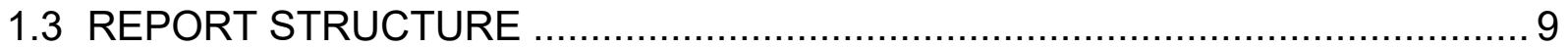

2.0 IMPACT OF SPEED MANAGEMENT STRATEGIES ON CONVENTIONAL

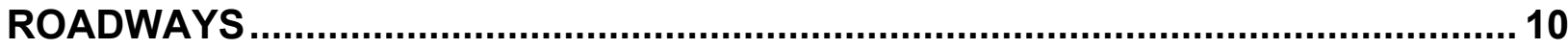

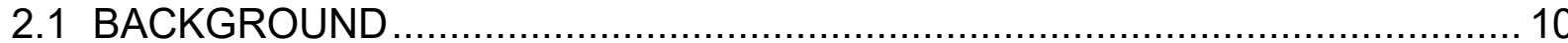

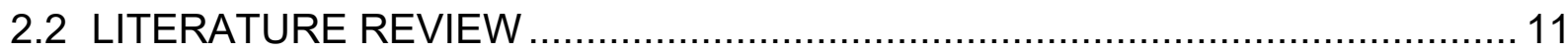

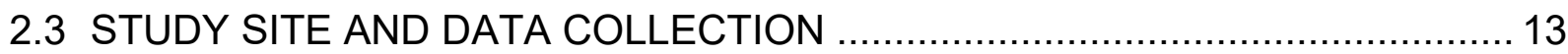

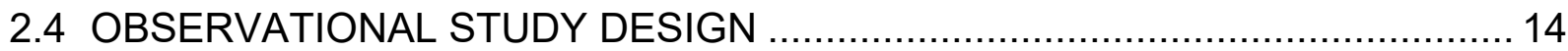

2.4.1 Traffic Flow Comparison................................................................... 14

2.5 IMPACT OF SFS ON INTERSECTIONS MOBILITY PERFORMANCE ............. 16

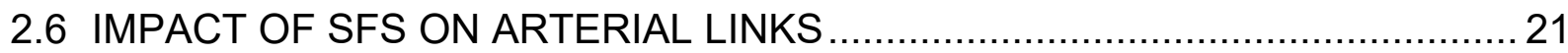

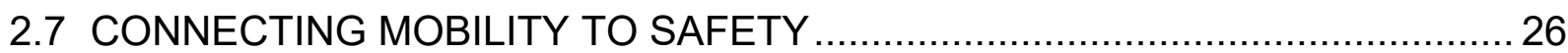

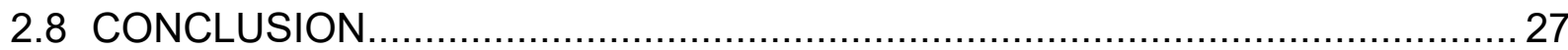

3.0 IMPACT OF SPEED MANAGEMENT STRATEGIES ON CONNECTED

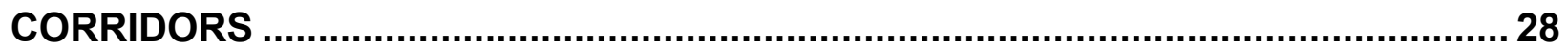

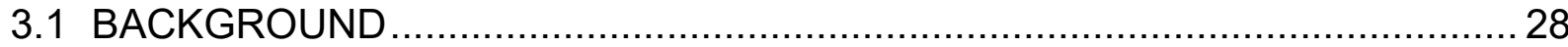

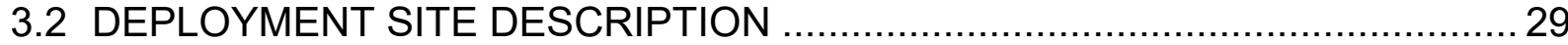

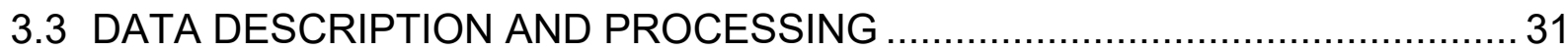

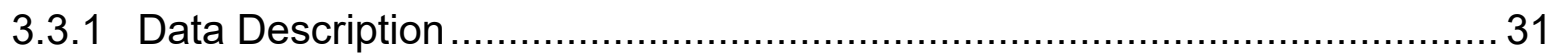

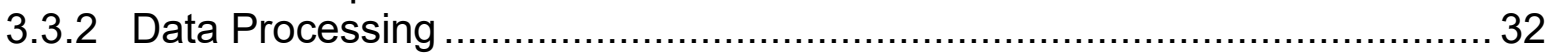

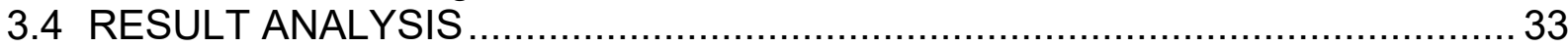

3.4.1 TSP Requested and TSP Served Analysis........................................... 33

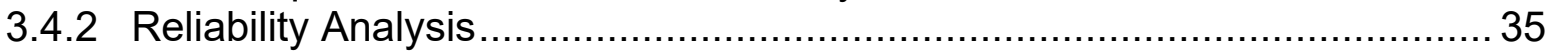

3.4.3 Travel/Running Time and Speed Analysis............................................. 35

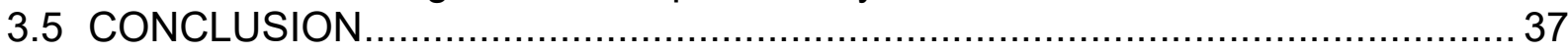

4.0 USING HIGH-RESOLUTION TRAFFIC DATA FOR EVALUATING

MULTIMODAL MOBILITY

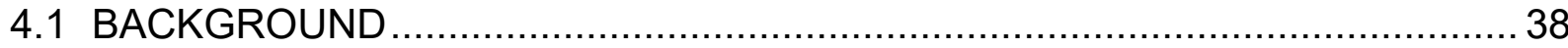

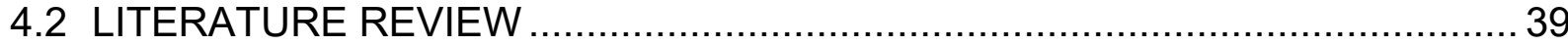

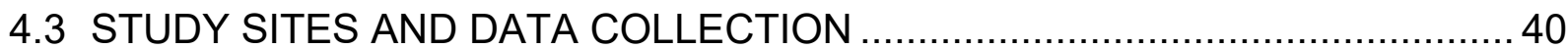

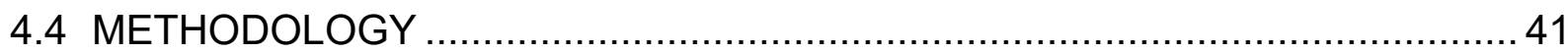

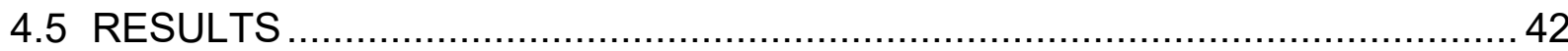

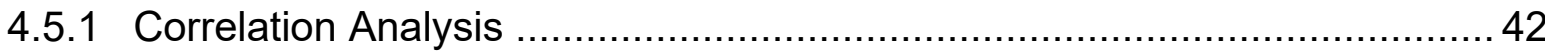

4.5.2 Model Development Analysis ...................................................... 43

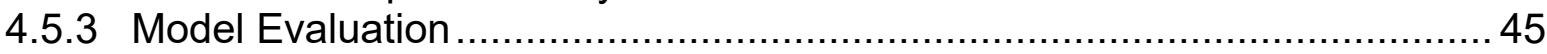

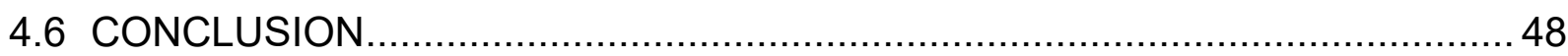

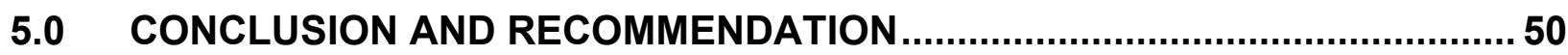

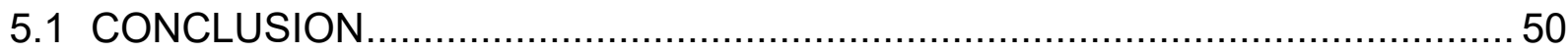

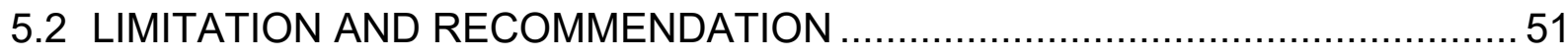

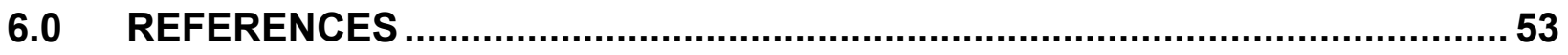




\section{LIST OF TABLES}

Table 2.1: Previous Studies on the Effectiveness of SFS ................................................... 12

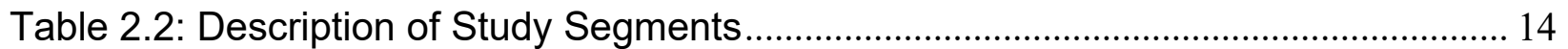

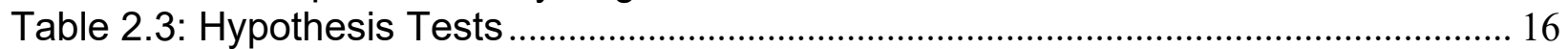

Table 2.4: Hypothesis Tests for Percent Arrivals on Red ............................................... 18

Table 2.5: Hypothesis Tests for Split Failure and Intersection Delay ................................. 20

Table 2.6: Link Speed and 85th Percentile Link Speed-Weekday ...................................... 21

Table 2.7: Link Speed And 85th Percentile Link Speed-Weekend ...................................... 21

Table 2.8: Results of Fitted Linear Mixed Models.............................................................. 24

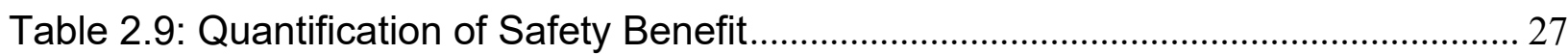

Table 3.1: Information of Broadcasted Messages through V2I ......................................... 30

Table 3.2: Rules to Define Bus Status at Each Timepoint ……………………………........ 32

Table 4.1 Detailed Information on the Selected Models .................................................... 44

Table 4.2 Comparison Results (Average Delay) ................................................................... 48

\section{LIST OF FIGURES}

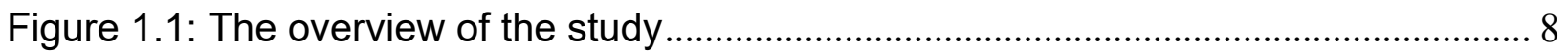

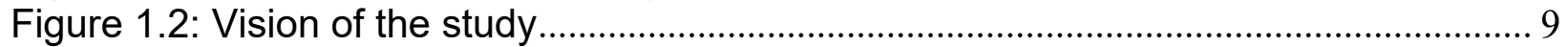

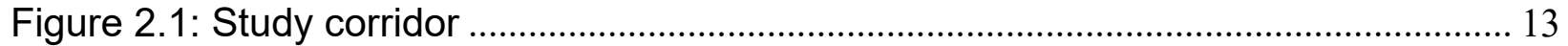

Figure 2.2: Traffic flow dispersion before and after disabling SFS ................................. 15

Figure 2.3: Density plot for arrivals on red; morning peak hours....................................... 19

Figure 2.4: Speed density distribution and speed box plot............................................... 22

Figure 2.5: Effectiveness of SFS; A) weekday, B) weekend............................................... 25

Figure 3.1: DSRC corridor for transit signal priority in Salt Lake City................................. 29

Figure 3.2: Available datasets diagram ............................................................................. 31

Figure 3.3: Rate of TSP requested and TSP served for various signal plans .................. 34

Figure 3.4: Reliability for northbound and southbound of route 217 before and after

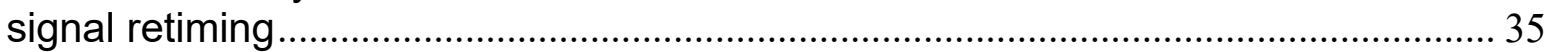

Figure 3.5: Bus travel time for northbound and southbound of route 217 before and after

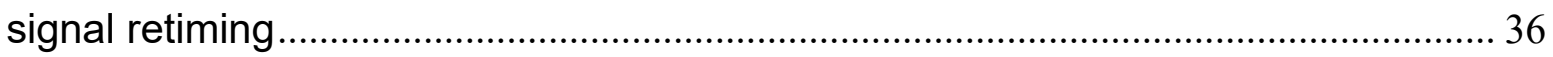

Figure 3.6: Bus running time for northbound and southbound of route 217 before and

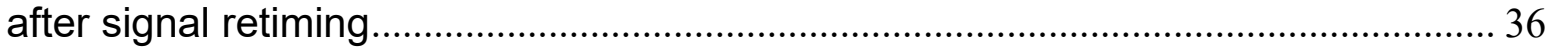

Figure 4.1: a) Ina Rd. Corridor; b) Sample ring barrier diagram........................................ 40

Figure 4.2: Correlation analysis among the covariates................................................... 42

Figure 4.3: Probability distribution function of pedestrian delay ........................................ 45

Figure 4.4: Model evaluation-average delay..................................................................... 47 


\section{EXECUTIVE SUMMARY}

Arterials account for more than one million miles of roadway, connecting local and collector roads to national highway systems (FHWA, 2020). Through the Moving Ahead for Progress in the 21st Century Act (MAP-21), the U.S. Congress requires that all the state Departments of Transportation (DOTs) and Multimodal Planning Organizations (MPOs) monitor, improve, and maintain the mobility and safety performance of their jurisdiction's road network, which includes arterials. Therefore, improving the arterials' traffic conditions is an essential part of every transportation improvement plan. Consequently, DOTs and MPOs are actively seeking to utilize increasingly ubiquitous ITS technologies to improve their roadway overall performance in terms of safety and mobility. Speed management strategies are one of the emerging ITS technologies that are being used by different states to improve the safety and mobility of their transportation network (Bagdade et al., 2012).

This study aims to investigate the possibility of developing and implementing more innovative speed management strategies that are effective for multimodal transportation and can be applied in both conventional and connected arterials. An effective strategy should consider both non-motorized and motorized modes of transportation. The three main objectives of this study are:

1. Evaluate the impact of speed management strategies along conventional arterials using smart sensor data.

2. Understand the role of conventional speed management strategies in supporting connected arterials.

3. Examine the possibility of using controller event-based data to estimate multimodal signal performance measures.

For the first objective of this study, the potential impact of speed feedback signs (SFS) on arterial mobility and safety was evaluated. For this objective, an observational before-after study was conducted on a conventional arterial road in Tucson, AZ. The impact of SFS on arterial mobility was evaluated at intersection and link levels. Then, the effect of SFS on the dispersion of operating speed was investigated by developing a speed change behavior model. Finally, the safety benefit of an active SFS were quantified at the link-speed level using the proposed driver speed change model. The results showed statistically significant speed reduction was found at three out of four links after enabling the SFS. In addition, it was found that the impact of SFS on drivers' behavior is a function of their approaching speed. The results of the safety assessment of SFS showed that at an arterial with a link speed of $35 \mathrm{mph}$, the benefit in dollar value 
per year associated with a reduction in the severe crash could pay as much as $\$ 700,000$.

For the second objective of this study, the impacts of the specific speed management, signal retiming, and coordination on transit signal priority (TSP) was evaluated on a connected corridor in Salt Lake City, UT. Results indicated that the ratio of TSP served is $33.12 \%$ before signal retiming, which is lower than that of $35.29 \%$ after signal retiming. As a result, the bus reliability for the northbound and southbound of the corridor improved by $2.65 \%$ and $1.21 \%$, respectively, after signal retiming. In addition, bus travel time and bus running time reduced after signal retiming, which resulted in improved bus speed after signal timing. All those measurements indicate that the speed management strategy implemented along this $\mathrm{CV}$ corridor results in an improvement of TSP.

Finally, the possibility of using controller event-based data to estimate multimodal signal performance measures was examined in a case study in Pima County, AZ. The results of estimating the pedestrian delay using the calibrated model at each intersection showed the proposed method was able to capture and track the actual delay fluctuation during the day with an average of $10 \%$ of mean absolute error. Further, the result of the test of disaggregated prediction showed that the proposed method was transferable to other intersections with similar specifications.

The study team provided the following recommendations for further investigating the possibility of developing and implementing more innovative data-driven mobility strategies for multimodal transportation that can be applied in both conventional and connected arterials:

1- An effective speed management strategy should concentrate on four primary "Es": Education, Engineering, Enforcement, and Emergency services. It is recommended that transportation agencies spend more resources on the Education element for enhancing public awareness on speeding issues.

2- Future research could focus on using real-time and historical third-party probebased data to identify the locations prone to speeding. Transportation agencies could benefit significantly from this type of information to relocate the law enforcement resources and optimally use all their available capacity.

3- To reduce the potential negative impact on other traffic while ensuring the efficiency of the connected buses, more studies need to be conducted to determine the potential of strategies in the future.

4- The high proportions of pedestrians experiencing delays greater than existing thresholds defined in the literature indicate that these intersections may be prone to higher risk-taking behaviors. It is recommended that related transportation agencies re-evaluate and revise their current signal timing, more specifically, adding a separate phase for pedestrians. 


\subsection{INTRODUCTION}

\subsection{STUDY BACKGROUND}

Arterials are the link in the transportation system providing mobility and access that has a bearing on the economy and quality of life (FHWA, 2020). Through the Moving Ahead for Progress in the 21st Century Act (MAP-21), the U.S. Congress requires that all the state Departments of Transportation (DOTs) and Multimodal Planning Organizations (MPOs) monitor, improve, and maintain the mobility and safety performance of their jurisdiction's road network. DOTs and MPOs are actively seeking to utilize increasingly ubiquitous technologies to improve mobility and safety on their roadway network. Generally, the overall performance of a transportation network is defined based on mobility and safety measures.

The mobility of road users and goods is the essential objective of an efficient transportation network. According to the Urban Mobility Report by the Texas Transportation Institute, traffic congestion on arterials caused commuters an extra 8.8 billion hours of delays, which impacted the fuel consumption of the users by an extra 3.3 billion gallons of gas (TTI, 2019). Improving roadway safety conditions for the users is another primary concern of every transportation agency. According to the World Health Organization, approximately 1.35 million people lose their lives in fatal accidents annually, and 20-50 million more people suffer from non-fatal accidents (WHO, 2020). In the United States, 36,560 people lost their lives due to traffic crashes in 2018 alone (NHTSA, 2018). Recently, with the emergence of new traffic sensors, data collection has become more manageable, which provides an excellent opportunity for DOTs and MPOs that need to implement intelligent transportation system (ITS) technologies to improve road safety and mobility (Karimpour \& Wu, 2021). Speed management strategies are one of the emerging ITS approaches that are being used by different states to improve the safety and mobility of their transportation network (Bagdade et al., 2012).

Speed management strategies are frameworks that aim to create safety and mobility for all road users. NHTSA defines speed management strategies as a balanced program that involves the relationship between speed, speeding, and safety (NHTSA., 2006). The main goal of speed management strategies is to improve mobility by reducing nonrecurrent delays and improving vehicle progression, public health, and traffic safety by reducing the number of speeding-related crashes. The primary three desirable outcomes of every speed management strategy are: reducing driver speed, increasing speed limit compliance, improving progression, and reducing the number of speedingrelated crashes (NHTSA, 2014). 
Currently, existing speed management strategies are mainly applicable to conventional arterials and are primarily developed for vehicles. With the recent advancement of sensing and communication technology, the transportation industry is now facing tremendous changes. The fast growth of cities, advancement in multimodal transportation planning, and the emergence of smart cities require us to develop more transferable mobility management strategies that can be used along all roadways and are able to incorporate all modes.

This study aims to investigate the possibility of developing and implementing more innovative speed management strategies that are effective for multimodal transportation and can be applied in both conventional and connected arterials. An effective strategy should consider both nonmotorized and motorized modes of transportation. Figure 1.1 illustrates the overview of this study. In this study, for the conventional arterial, the effectiveness of conventional speed management strategies, such as speed feedback signs, on corridor safety and mobility will be evaluated. In addition, by using the controller event-based data collected from the

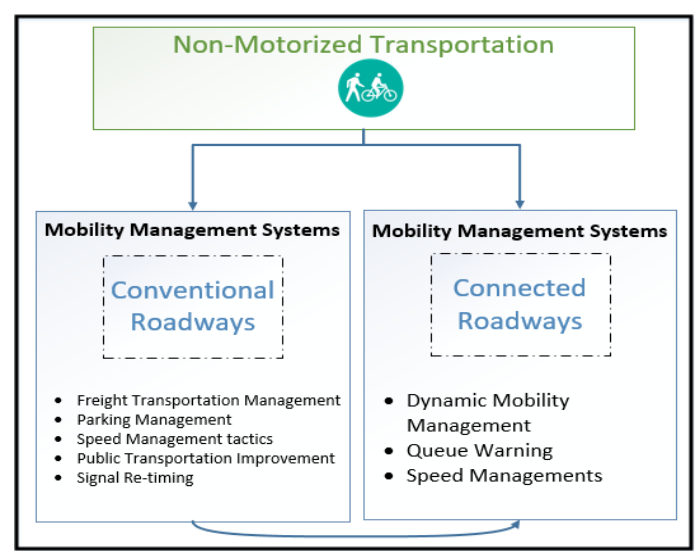

Figure 1.1: The overview of the study smart sensors, multimodal signal performance measures such as pedestrian delay will be estimated. For the connected arterial, the impacts of the specific speed management strategies, signal retiming and coordination on transit signal priority (TSP) will be examined.

\subsection{STUDY OBJECTIVES}

Figure 1.2 demonstrates the vision of this study. With the advancement in technology (x-axis) the conventional arterials are slowly transforming into connected arterials. In addition, with the growth in the scale of technology (y-axis) nowadays, smart cities are serving more mixed traffic (e.g., walking, cycling, automobile, public transit, etc.) rather than vehicle-only traffic. Therefore, comprehensive and effective speed management strategies should be developed to serve the multimodal transportation network in both conventional and connected arterials. In addition, it should consider the safety of cyclists and pedestrians in the network. 


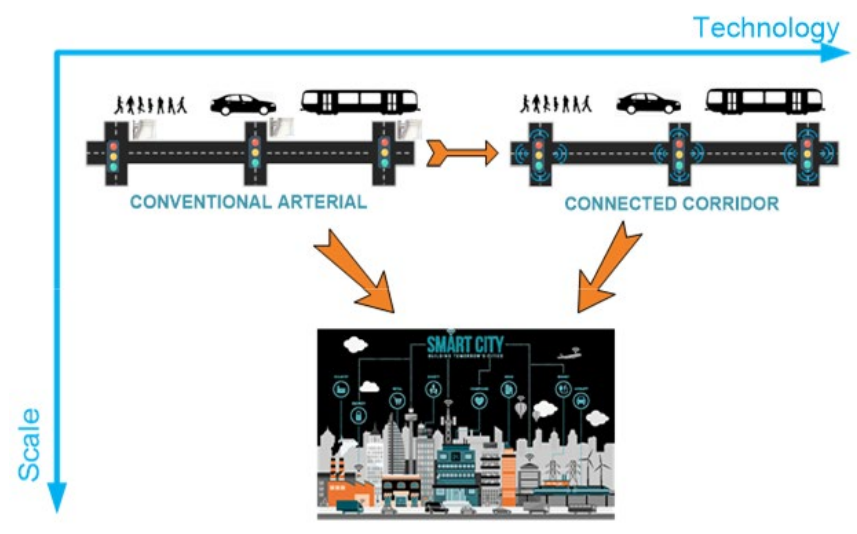

Figure 1.2: Vision of the study

The three main objectives of this study are:

1. Evaluate the impact of speed management strategies along conventional arterials using smart sensor data.

2. Understand the role of conventional speed management strategies in supporting connected corridors.

3. Examine the possibility of using controller event-based data to estimate multimodal signal performance measures.

The outcomes of this study will assist practitioners, such as the Utah Department of Transportation (UDOT) and the Pima County Department of Transportation (PCDOT) in Arizona to find the most effective and efficient multimodal traffic management strategies in urban regions. This research will also help policymakers understand how eventbased data collected from smart sensors can be beneficial in the transition to smart cities.

\subsection{REPORT STRUCTURE}

The remainder of this report is structured as described herein. Chapter 2 will discuss the impact of conventional speed management strategies at arterial and intersection levels. In this chapter, the mobility and safety impact of speed feedback signs, a conventional speed management strategy, at arterial and intersection levels will be evaluated. In Chapter 3, the impact of speed management strategies on connected roadways will be examined. In this chapter, the impact of signal retiming and progression on TSP will be evaluated. Next, in Chapter 4, the possibility of using controller event-based data to estimate multimodal signal performance measures will be examined. Finally, Chapter 5 will provide conclusions and recommendations. 


\subsection{IMPACT OF SPEED MANAGEMENT STRATEGIES ON CONVENTIONAL ROADWAYS}

This chapter discusses the mobility and safety impact of speed feedback signs (SFS) at corridor and intersection levels on conventional roadways. The evaluation was conducted on a major east/west corridor in Pima County, AZ. This chapter is prepared based on a published journal article (Karimpour et al., 2020a).

\subsection{BACKGROUND}

Growth in both population and car ownership per capita directly impacts the mobility and safety of the nation's roadways. Through the Moving Ahead for Progress in the 21st Century Act (MAP-21), the U.S. Congress requires that all state Departments of Transportation (DOTs) and Multimodal Planning Organizations (MPOs) monitor, improve, and maintain the mobility and safety performance of their jurisdiction's road network. DOTs and MPOs are actively seeking to utilize increasingly ubiquitous technologies to improve mobility and safety on their roadway network. Generally, the overall performance of a transportation network is defined based on mobility and safety measures. With the limitation of infrastructure and growth in people using vehicles, agencies are required to develop the most effective and practical type of speed management strategy to impose the speed limit. Speed management strategies are one of the emerging ITS approaches that are being used by different states to improve the safety and mobility of their transportation network (Bagdade et al., 2012).

Speed management strategies are frameworks that aim to create safety and mobility for all road users. The main goal of speed management strategies is to improve mobility by reducing nonrecurrent delays and improving vehicle progression, public health, and traffic safety by reducing the number of speeding-related crashes. The primary three desirable outcomes of every speed management strategy are reducing driver speed, increasing speed limit compliance, and reducing the number of speeding-related crashes (NHTSA, 2014; Karimpour, 2020).

In this chapter, the following two questions are aimed to be answered:

1- What is the impact of speed feedback signs (SFS) on the intersection mobility performance?

2- What is the impact of SFS on the signalized arterial mobility and safety?

At the intersection level, the impact of SFS on intersection signal performance measures, such as simple delay, arrival on red, will be evaluated. Further, at the arterial 
level, the impact of using SFS on reducing the segment-based speed and crash frequency will be evaluated.

This chapter is structured as described herein. In the first section, a comprehensive literature review on the effectiveness of SFS is provided. Then, the observational framework and results used for evaluating the impact of SFS on intersection mobility are discussed. Next, the impact of SFS on corridor mobility and safety is explained. Finally, the conclusions and recommendations for future research are provided.

\subsection{LITERATURE REVIEW}

Excessive speed is a crucial traffic safety concern on almost all types of roadways. Speeding is the key contributing factor to many crashes (Imprialou et al., 2016; PourRouholamin \& Zhou, 2016). A study reported by the World Health Organization (WHO) stated that an increase of $0.6 \mathrm{mph}$ in average speed could increase the risk of an injury crash by $3 \%$ and increase the risk of a fatal crash by $4-5 \%$. Overall, drivers with speeds higher than the posted speed will have a higher risk of a severe crash (Aarts \& Van Schagen, 2006; Rune \& Vaa, 2009). Recently, with the emergence of new technologies, ITS solutions, and various data-driven approaches to improve mobility and safety in the transportation network are evolving (Ariannezhad \& Wu, 2020; Joerger \& Hassani, 2020; Karimpour et al., 2019; Ma et al., 2020). Real-time crash prediction (Ariannezhad et al., 2021); microlevel and macrolevel (Ariannezhad et al., 2020; Ariannezhad \& Wu, 2019; Mousavi et al., 2021); safety and integrity analysis, and hotspot prediction analysis (Hassani et al., 2018; Hassani et al., 2019; Mansourkhaki, Karimpour, \& Sadoghi Yazdi, 2017; Mansourkhaki, Karimpour, \& Yazdi, 2017); and speed management strategies (Bagdade et al., 2012; NHTSA, 2014) are some of the innovative data-driven approaches recently adopted by transportation engineers to enhance roadway mobility and safety.

SFS, or dynamic speed display signs, are one of the most popular fixed speed management strategies. SFS are interactive signs that display the approaching vehicle's speed until it surpasses a predefined threshold, after which they will alert the driver of speeding through either a word message of "Slow Down" or a flashing light. SFS are mainly deployed for traffic calming at locations with a history of extreme overspeeding (Cruzado \& Donnell, 2009; Karimpour, Kluger, et al., 2021; Karimpour et al., 2020); sensitive road segments such as work zones (Ullman \& Rose, 2005); and school zones (Lee et al., 2006) or in locations where failure to comply with the speed limit can be especially hazardous due to the geometric road designs such as curves or operational changes such as speed transition zones (Cruzado \& Donnell, 2009). Compared to other strategies, SFS are low-cost and effective in influencing the vehicle operating speed (Gehlert et al., 2012). Pesti and McCoy (2001) studied SFS along a 2.7-mile work zone on I-80. Their results showed a statistically significant reduction in operating speed and an increase in speed limit compliance during the study period. Ulman and Rose studied multiple SFS in school zones and on horizontal curves and showed that SFS were effective in reducing the average speed by $9 \mathrm{mph}$ in school zones and less than $5 \mathrm{mph}$ on horizontal curves (Ullman \& Rose, 2005). Lee et al. (2006) examined SFS in two school zones and examined the impact of SFS during the 
short term after installation. The results showed that an SFS were able to reduce the average speed by $17.5 \%$ throughout the day. However, a major issue with SFS is the halo effect (De Pauw et al., 2014b): drivers only abruptly decelerate their speed in the immediate vicinity of the enforcement zone, and after passing the enforcement zone they will quickly regain their speed. The halo effect has been shown to exist not only for SFS (Ardeshiri \& Jeihani, 2014; Santiago-Chaparro et al., 2012), but also for other fixed speed enforcement strategies, such as speed enforcement cameras (Champness et al., 2005; De Pauw et al., 2014a) and the monitored speed section (Ragnøy, 2011). It was shown that drivers resume their speeding habits typically within 1,000 meters of exiting the monitored speed location (Ragnøy, 2011). Table 2.1 summarizes all the studies conducted on the effectiveness of SFS from 2000 to 2020.

Table 2.1: Previous Studies on the Effectiveness of SFS

\begin{tabular}{|c|c|c|c|}
\hline Authors & Year & Roadway Type & Impact (comments) \\
\hline Carlson et al. & 2000 & Work zone & $\begin{array}{ll}\text { - } & \text { Reduction in the average speed } \\
\text { - } & \text { Increase in the speed limit compliance }\end{array}$ \\
\hline $\begin{array}{l}\text { Pesti and } \\
\text { McCoy }\end{array}$ & 2001 & Work zone & $\begin{array}{ll}\text { - } & \text { Reduction in average speed } \\
\text { - } & \text { Increase in the speed limit compliance }\end{array}$ \\
\hline Ulman and Rose & 2005 & $\begin{array}{l}\text { School zone; } \\
\text { Horizontal curve; } \\
\text { Speed transition } \\
\text { zone }\end{array}$ & $\begin{array}{l}\text { - Average speed reduced by } 9 \mathrm{mph} \text { in the } \\
\text { school zone } \\
\text { - Average speed reduced by less than } 5 \\
\text { mph in other locations }\end{array}$ \\
\hline Lee et al. & 2006 & School zone & $\begin{array}{l}\text { - Short-term effect: average speed } \\
\text { reduced by } 17.5 \% \\
\text { - Long-term effect: average speed } \\
\text { reduced by } 12.5 \%\end{array}$ \\
\hline Wrapson et al. & 2006 & $\begin{array}{l}\text { Two-lane urban } \\
\text { road }\end{array}$ & - $\quad$ Average speed reduced by $6 \mathrm{mph}$ \\
\hline Sandberg et al. & 2006 & Transition zones & $\begin{array}{ll}\text { - } & \text { Average speed reduced by } 6 \text { to } 8 \mathrm{mph} \\
\text { - } & \text { Increase in the speed limit compliance }\end{array}$ \\
\hline $\begin{array}{l}\text { Cruzado and } \\
\text { Donnell }\end{array}$ & 2009 & Transition areas & $\begin{array}{ll}\text { - } & \text { Average speed reduced by } 6 \mathrm{mph} \\
\text { - } & \text { Increase in the speed limit compliance }\end{array}$ \\
\hline $\begin{array}{l}\text { Walter and } \\
\text { Broughton }\end{array}$ & 2011 & $\begin{array}{l}\text { Single-lane urban } \\
\text { roads }\end{array}$ & - $\quad$ Average speed reduced by $1.4 \mathrm{mph}$ \\
\hline Gehlert et al. & 2012 & $\begin{array}{l}\text { Two-lane local } \\
\text { main street }\end{array}$ & $\begin{array}{ll}\text { - } & \text { Reduction in the average speed } \\
\text { - } & \text { Reduction in the 85th percentile of speed } \\
\text { - } & \text { Increase in the speed limit compliance }\end{array}$ \\
\hline $\begin{array}{l}\text { Ardeshiri and } \\
\text { Jeihani }\end{array}$ & 2014 & $\begin{array}{l}\text { Three corridors } \\
\text { with different } \\
\text { speed limits }\end{array}$ & $\begin{array}{l}\text { Speed limit compliance increased by } 5 \% \\
\text { Average speed was reduced in more } \\
\text { than } 40 \% \text { of the cases }\end{array}$ \\
\hline Hallmark et al. & 2015 & Nationwide study & $\begin{array}{l}\text { Average speed reduction was } 1.82 \mathrm{mph} \text {, } \\
2.57 \mathrm{mph} \text {, and } 1.97 \mathrm{mph} \text { on average for } \\
\text { all the sites }\end{array}$ \\
\hline
\end{tabular}




\begin{tabular}{|c|c|c|c|c|}
\hline Zineddin et al. & 2016 & $\begin{array}{c}\text { Two-lane rural } \\
\text { curves } \\
\text { Nine sites in } \\
\text { major arterials- } \\
\text { supported SFS } \\
\text { with periodic law } \\
\text { enforcement }\end{array}$ & $\begin{array}{l}\text { - } \\
\text { Karimpour et al. } 2021\end{array}$ & $\begin{array}{l}\text { On average, most sites had a reduction } \\
\text { in the average speed by almost 11 mph }\end{array}$ \\
\hline & $\begin{array}{l}\text { Supporting SFS with periodic law } \\
\text { enforcement is more effective in } \\
\text { reducing average speed and the } \\
\text { percentage of vehicles exceeding the } \\
\text { speed limit than SFS only, compared to } \\
\text { SFS only } \\
\text { Supporting speed feedback with periodic } \\
\text { law enforcement can eliminate the halo } \\
\text { effect }\end{array}$ \\
\hline
\end{tabular}

\subsection{STUDY SITE AND DATA COLLECTION}

Ina $\mathrm{Rd}$, a major signalized arterial in Tucson, $\mathrm{AZ}$, with a speed limit of $45 \mathrm{mph}$, was selected as the study corridor. Ina Rd is a multimodal arterial that moves traffic eastwest with access to Interstate 10. Four segments shown in Figure 2.1 were used as study sites.

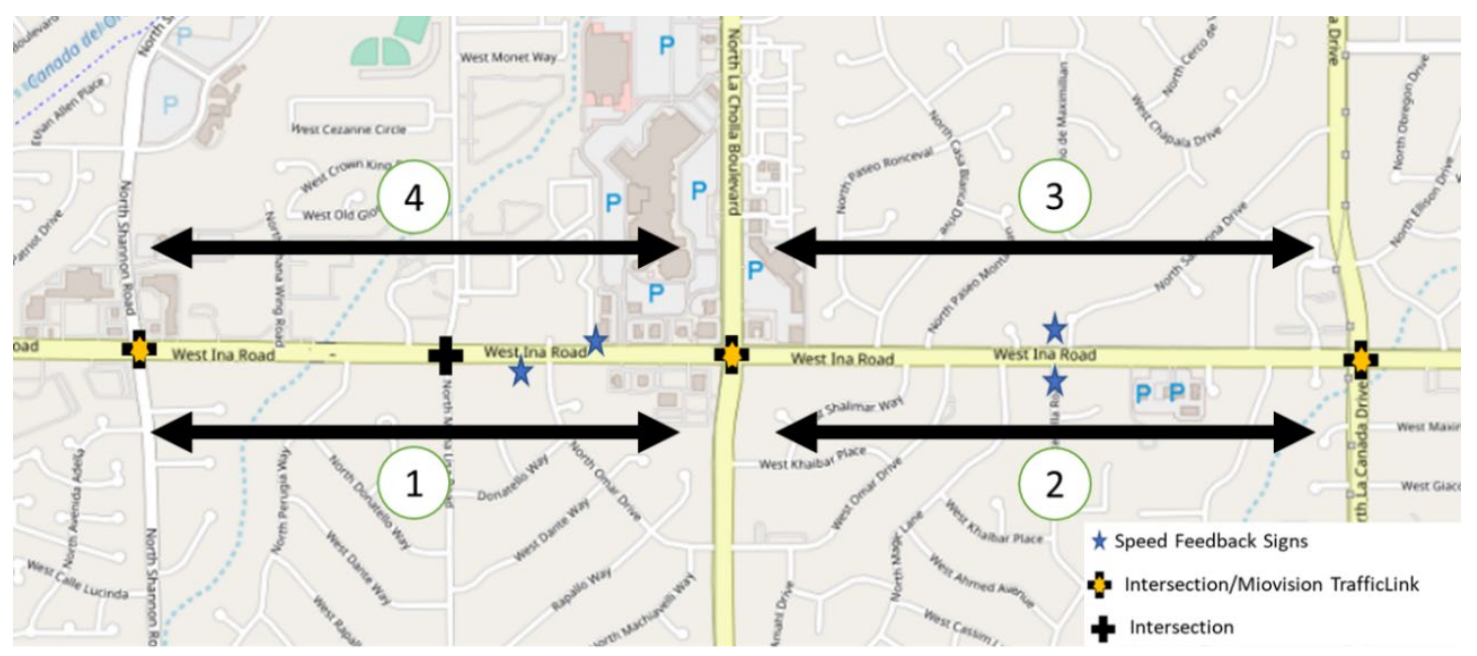

Figure 2.1: Study corridor

SFS were installed in advance of each intersection, and a MioVision TrafficLink (MioVision Team, 2019) unit was installed at each intersection, providing real-time performance metrics through an online platform. This corridor was selected because of the existing SFS installed by PCDOT along the corridor between signalized intersections and due to the presence of advanced traffic data collection systems. The corridor operates on a coordinated plan during peak hours, and the signals operate independently in the off-peak hours. Table 2.2 lists the four study segments, including the segment length, speed limit, upstream and downstream intersection, and the distance of each SFS to the downstream intersection. 
Table 2.2: Description of Study Segments

\begin{tabular}{|c|c|c|c|c|c|c|c|}
\hline $\begin{array}{c}\text { Segment } \\
\text { ID }\end{array}$ & Direction & County & $\begin{array}{c}\text { Upstream } \\
\text { Intersection }\end{array}$ & $\begin{array}{c}\text { Downstream } \\
\text { Intersection }\end{array}$ & $\begin{array}{c}\text { Segment } \\
\text { Length } \\
\text { (miles) }\end{array}$ & $\begin{array}{c}\text { SFS } \\
\text { Distance to } \\
\text { Downstream } \\
\text { (miles) }\end{array}$ & $\begin{array}{c}\text { Speed } \\
\text { Limit } \\
\text { (mph) }\end{array}$ \\
\hline $\mathbf{1}$ & Eastbound & Pima & $\begin{array}{c}\text { N Shannon } \\
\text { Rd. }\end{array}$ & $\begin{array}{c}\text { N La Cholla } \\
\text { Blvd. }\end{array}$ & 0.98 & 0.24 & 45 \\
\hline $\mathbf{2}$ & Eastbound & Pima & $\begin{array}{c}\text { N La Cholla } \\
\text { Blvd. }\end{array}$ & $\begin{array}{c}\text { N La Canada } \\
\text { Dr. }\end{array}$ & 1.02 & 0.4 & 45 \\
\hline $\mathbf{3}$ & Westbound & Pima & $\begin{array}{c}\text { N La } \\
\text { Canada Dr. }\end{array}$ & $\begin{array}{c}\text { N La Cholla } \\
\text { Blvd. }\end{array}$ & 1.02 & 0.47 & 45 \\
\hline $\mathbf{4}$ & Westbound & Pima & $\begin{array}{c}\text { N La Cholla } \\
\text { Blvd. }\end{array}$ & $\begin{array}{c}\text { N Shannon } \\
\text { Rd. }\end{array}$ & 0.98 & 0.38 & 45 \\
\hline
\end{tabular}

\subsection{OBSERVATIONAL STUDY DESIGN}

Traffic data were collected for four weeks (May 28-June 25, 2018), and the existing signs were disabled for two weeks (June 11th-June 25th) during the data collection. To evaluate the intersection mobility operations, three performance measures were collected at each intersection using MioVision's TrafficLink platform (MioVision Team, 2019), including, percentage arrival on red, intersection delay, and split failures. Percentage of arrival on red, split failure, and intersection delay were collected using high-resolution controller event-based data. The definition of each performance measure is:

1- Percentage arrival on red: This measure shows the percentage of vehicles that arrived at the intersection when the signal was red.

2- Intersection delay: Total amount of time that all vehicles spend in the intersection queue while waiting to pass the intersection.

3- Split failure: The occurrence of leftover demand for a specific approach at an intersection.

It indicates at least one vehicle from the queue was not served during the cycle. The first four measures were collected at the intersection level. The last measure, link speed, was collected at a link level. A link is the roadway segment between two intersections.

\subsubsection{Traffic Flow Comparison}

Using the performance measures collected from Miovision sensors, the potential impact of SFS on arterial safety and mobility was evaluated. The evaluation was conducted at the link and intersection levels. The Highway Capacity Manual (HCM) recommends using control delay and queue length for evaluating the intersection performance measure, and travel time and travel speed as the corridor performance measure (Urbanik et al., 2015). In addition, many studies suggested using arrivals on green/red and split failure for evaluating corridor and intersection performance (Day, Bullock, et 
al., 2016; Day et al., 2018; Remias et al., 2018). For instance, Day et al. (2018) evaluated the improvement of signalized intersection performance after retiming and coordinating the intersections on SR 77 in Indiana using the arrival on red and arrival on green measures. Similarly, in this study, percentage of arrival on red, intersection delay, and split failure were used as the intersection-level measures, and link speed was used as the corridor level measure.

Before conducting the before-and-after comparison of the measures, aggregated traffic flow from major and minor streets was used to capture the possible fluctuation of traffic flow during the study period. Figure 3 illustrates the average hourly traffic flow for the study segments during the study periods.
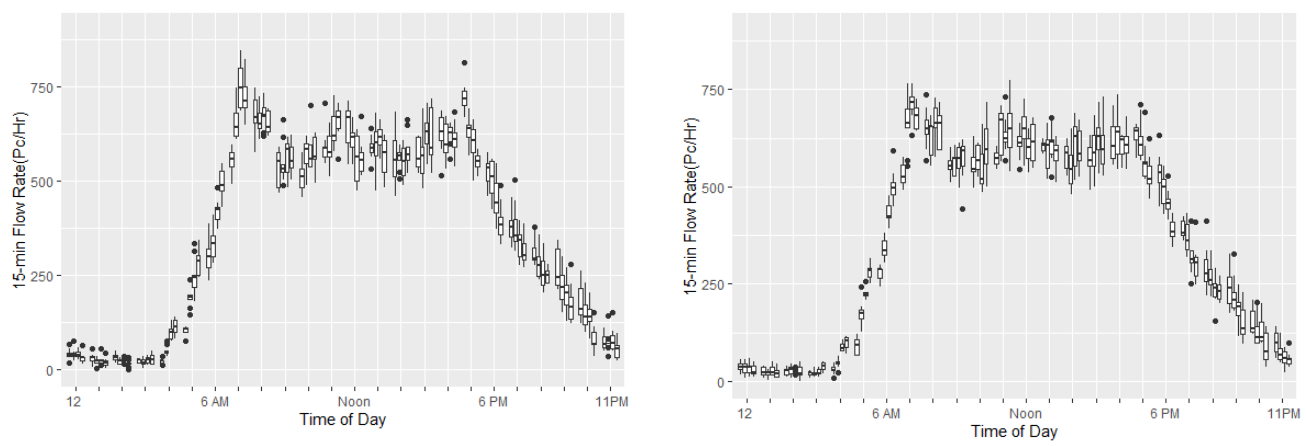

Segment 2: Eastbound from N La Cholla Blvd. to N La Canada Dr.
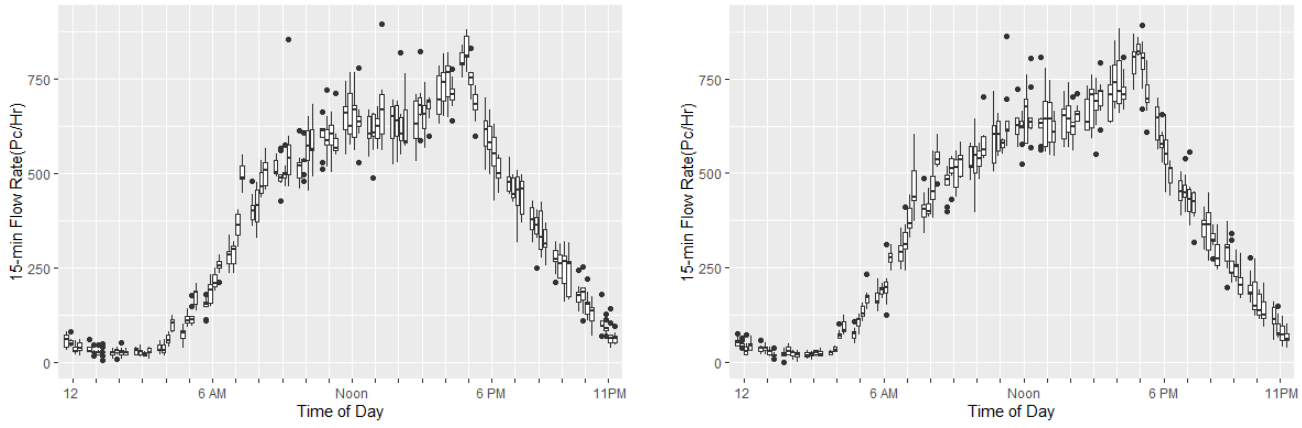

Segment 3: Westbound from N La Canada Dr. to N La Cholla Blvd.
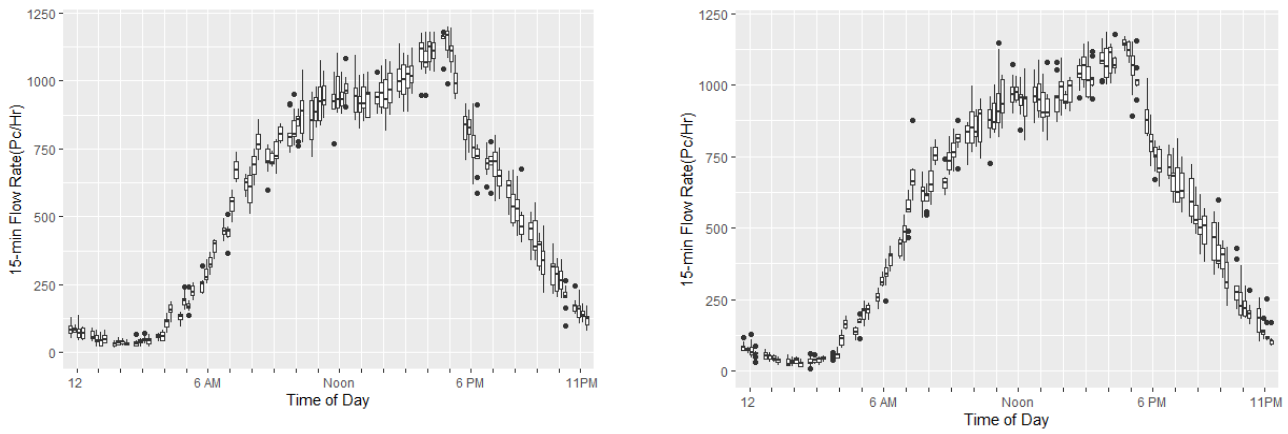

Segment 4: Westbound from N La Cholla Blvd. to N Shannon Rd.

Figure 2.2: Traffic flow dispersion before and after disabling SFS 
Based on Figure 2.2, for a given time of day before and after disabling SFS, only a little variation in traffic flow was observed. Similar traffic flow peaks for all the segments suggest that traffic flow was not affected by disabling the SFS.

In the next section, the mobility impact of SFS on intersection and corridor will be evaluated. In addition, to evaluate the impact of SFS on driver behavior, the drivers' speed change behavior models will be developed.

\subsection{IMPACT OF SFS ON INTERSECTIONS MOBILITY PERFORMANCE}

The mobility impact of SFS were evaluated at intersection and corridor levels. To evaluate the impact of SFS at an intersection level, several signal performance measures were used and a before-after study framework was designed as in Table 3. $A R, S F$, and $D e$ are the segment percentage arrival on red, split failure, and intersection delay, respectively. In Table 3 , the null hypothesis $\left(H_{0}\right)$ states that the population means (e.g., arrival on red) are equal between the related segments before and after disabling the SFS, and the alternative hypothesis $\left(H_{a}\right)$ states that the population means (e.g., mean travel time) are not equal between the related segments before and after disabling the SFS (i.e., for at least one segment the population means before and after disabling the SFS is different). Table 2.3 illustrates the hypotheses developed for the mean $(\mu)$ value of each measure. Similar hypotheses were also developed for the variance of each measure $\left(\sigma^{2}\right)$.

Table 2.3: Hypothesis Tests

\begin{tabular}{|c|c|}
\hline Hypothesis Tests & Other statistics \\
\hline 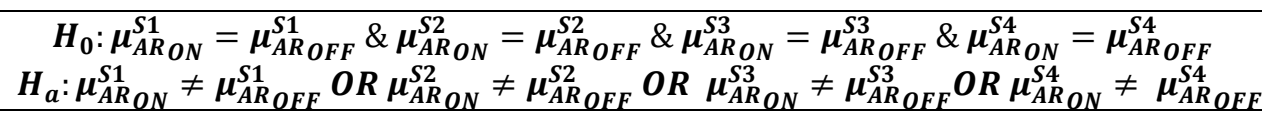 & Variance $\left(\sigma^{2}\right)$ \\
\hline 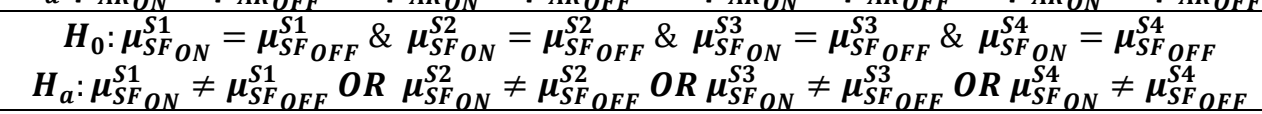 & Variance $\left(\sigma^{2}\right)$ \\
\hline 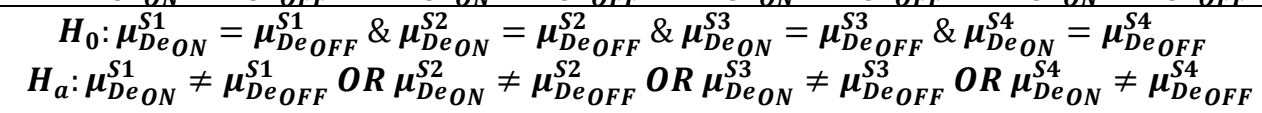 & Variance $\left(\sigma^{2}\right)$ \\
\hline
\end{tabular}

It is worthwhile to mention that the logical operator used for the alternative hypotheses is "OR," meaning that the null hypothesis could be rejected if at least one mean (or other respective parameters) is different in related segments for the before-and-after condition.

To develop the hypotheses in Table 2.3, parametric or non-parametric statistical tests that examine the differences between the selected performance measures (e.g., mean delay, the variance of delay) before and after disabling the SFS should be used. Generally, tests with repeated measures are the best approach to find the difference between a treatment (in this case, SFS or No SFS) across multiple attempts (in this case, different segments) (von Ende, 2001; Gueorguieva and Krystal, 2004). However, 
before using parametric tests with repeated measures, such as ANOVA with repeated measures, two assumptions of population normality and homogenously of variance among treatments need to be tested (Vincent \& Weir, 1999). In this study, these assumptions were tested using Kolmogorov-Smirnov (K-S) tests, and the results showed that none of the measures in this study conformed to a normal distribution. Therefore, an appropriate alternative non-parametric test was selected.

Compared to more traditional parametric tests, non-parametric tests have fewer assumptions regarding the underlying distribution of the population. Moreover, the assumption of the equal variance of the populations can be ignored by using ranks in non-parametric approaches. Since the Friedman test (Friedman, 1937) does not assume a particular distribution (i.e., normal) for the data, and is a standard test to compare treatments across blocks (Zimmerman \& Zumbo, 1993), it is a suitable nonparametric test for our study. In the Friedman test, the null hypothesis states that responses from different treatments have the same or similar distributions (Pereira et al., 2015; Siegal, 1956).

To develop the Friedman test statistic, the measures (e.g., delay) are formatted into a matrix with $N$ rows and $K$ columns (Benavoli et al., 2016); $K$ denotes the treatments and $N$ denotes the number of blocks for each treatment. Assume we have a matrix in the form of $\left\{x_{i, j}\right\}_{N, K}$ :

$$
x_{i, j}=\left[\begin{array}{cccc}
x_{1,1} & x_{1,2} & x_{1,3} & \ldots \\
x_{2,1} & x_{2,2} & x_{2,3} & \ldots \\
x_{3,1} & x_{2,3} & \ddots & \ldots \\
\vdots & \vdots & \vdots & x_{N, K}
\end{array}\right]
$$

where the columns represent each treatment (i.e., before and after disabling the SFS), and the rows represent each block (for our study, the measures are collected from four segments). Now, denote $r_{i j}$ as a new matrix of $\left\{r_{i, j}\right\}_{N, K}$, where $r_{i j}$ is the rank of $x_{i, j}$ within each attempt, the test statistic $T$ for the Friedman test is defined by Equation (2-1) (Siegal, 1956):

$$
T=\frac{N \sum_{j=1}^{K}\left(\bar{r}_{. j}-\bar{r}\right)^{2}}{\frac{1}{N(K-1)} \sum_{i=1}^{N} \sum_{j=1}^{K}\left(r_{i j}-\bar{r}\right)^{2}}
$$

where:

$$
\begin{gathered}
\bar{r}_{. j}=\frac{1}{N} \sum_{i=1}^{N} r_{i j} \\
\bar{r}=\frac{1}{N K} \sum_{i=1}^{N} \sum_{j=1}^{K} r_{i j}
\end{gathered}
$$


where $N$ is the number of blocks, $K$ is the number of treatments, and $T$ is the test statistic. As $N$ approaches infinity, $T$ will follow a Chi-Square distribution with $K-1$ degrees of freedom. A study conducted by Zimmerman and Zumbo (Zimmerman \& Zumbo, 1993) showed that the Friedman test pattern is essentially the same, whether using two treatments, three treatments, or many treatments. In our study, $K=2$ and is the number of treatments (before and after disabling the SFS), and the number of blocks, $N=4$, is the number of segments. Based on a study done by Pereira et al. (2015) for a small value of $K$ and $N$, the exact critical values should be directly used from available tables (Pereira et al., 2015).

To include the time factor in our analysis, the hypothesis tests in Table 2.3 were implemented for morning-peak, afternoon-peak, and off-peak hours during the weekdays. To evaluate the impact of SFS on percent arrivals on red, the hypotheses were developed based on two statistics: mean and variance of percent arrivals on red. The hypotheses will be used to test whether there is any difference between the parameters associated with the percent arrivals on red before and after disabling the SFS. For instance, the hypothesis for mean percent arrivals on red was as below:

$$
\begin{aligned}
& H_{0}: \mu_{A R O N}^{S 1}=\mu_{A R O F F}^{S 1} \& \mu_{A R O N}^{S 2}=\mu_{A R O F F}^{S 2} \& \mu_{A R O N}^{S 3}=\mu_{A R O F F}^{S 3} \& \mu_{A R O N}^{S 4}=\mu_{A R O F F}^{S 4} \\
& H_{a}: \mu_{A R}^{S 1} \neq \mu_{A R O F F}^{S 1} \text { OR } \mu_{A R O N}^{S 2} \neq \mu_{A R O F F}^{S 2} \text { OR } \mu_{A R O N}^{S 3} \neq \mu_{A R O F F}^{S 3} \text { OR } \mu_{A R O N}^{S 4} \neq \mu_{A R O F F}^{S 4}
\end{aligned}
$$

The null hypothesis $\left(H_{0}\right)$ states that the mean percent arrivals are equal between the related segments before and after disabling the SFS, and the alternative hypothesis $\left(H_{a}\right)$ states that at least one of the mean percent arrivals are not equal between the related segments before and after disabling the SFS. Similar null and alternative hypotheses were also developed for the variance of percent arrivals on red. Table 2.4 illustrates the summary result of the hypotheses and the corresponding $p$-values for each test.

\begin{tabular}{|c|c|c|c|c|c|}
\hline & Friedman Test & Period & $\begin{array}{c}\text { Chi- } \\
\text { Square } \\
\left(X^{2}\right)\end{array}$ & $\begin{array}{c}\text { P- } \\
\text { Value }\end{array}$ & Decision $^{*}$ \\
\hline \multirow{3}{*}{ Mean } & \multirow{3}{*}{$\begin{array}{l}H_{0}: \mu_{A R O N}^{S i}=\mu_{A R O F F}^{S i} \\
H_{a}=\text { for at least one segment, the mean } \\
\text { percent arrival on red before and after } \\
\text { disabling the SFS is different }\end{array}$} & $\begin{array}{l}\text { AM- } \\
\text { Peak }\end{array}$ & 6 & 0.11 & $x$ \\
\hline & & $\begin{array}{l}\text { PM- } \\
\text { Peak }\end{array}$ & 6 & 0.11 & $x$ \\
\hline & & $\begin{array}{c}\text { Off- } \\
\text { Peak }\end{array}$ & 6 & 0.11 & $x$ \\
\hline \multirow{3}{*}{ Variance } & \multirow{3}{*}{$\begin{array}{l}H_{0}: \sigma_{A R O N}^{2 S i}=\sigma_{A R O F F}^{2 S i} \\
H_{a}=\text { for at least one segment, the variance } \\
\text { of percent arrival on red before and after } \\
\text { disabling the SFS is different }\end{array}$} & $\begin{array}{l}\text { AM- } \\
\text { Peak }\end{array}$ & 6 & 0.11 & $x$ \\
\hline & & $\begin{array}{l}\text { PM- } \\
\text { Peak }\end{array}$ & 5.4 & 0.14 & $x$ \\
\hline & & $\begin{array}{l}\text { Off- } \\
\text { Peak }\end{array}$ & 6 & 0.11 & $x$ \\
\hline
\end{tabular}

Table 2.4: Hypothesis Tests for Percent Arrivals on Red

${ }^{*}$ Fail to reject $(\boldsymbol{X})$, Reject $(\boldsymbol{V})$; SF: Intersection Split Failure; De: Intersection Delay 
Results from Table 2.4 indicate that, at a significance level of $\alpha=0.05$, there is not sufficient evidence to reject the null hypothesis. In other words, based on these results, the operation of SFS does not have a statistically significant impact on the percent arrivals on red. To visualize the results from Table 2.4, the density plot for the percent arrivals on red for the morning peak hours during the study period is illustrated in Figure 2.3. The gray dashed lines show the conditions when the SFS were active, and the black solid lines show the conditions when the SFS were off. The distribution of the percent arrivals on red, before and after disabling the SFS, have similar peaks for each of the segments.
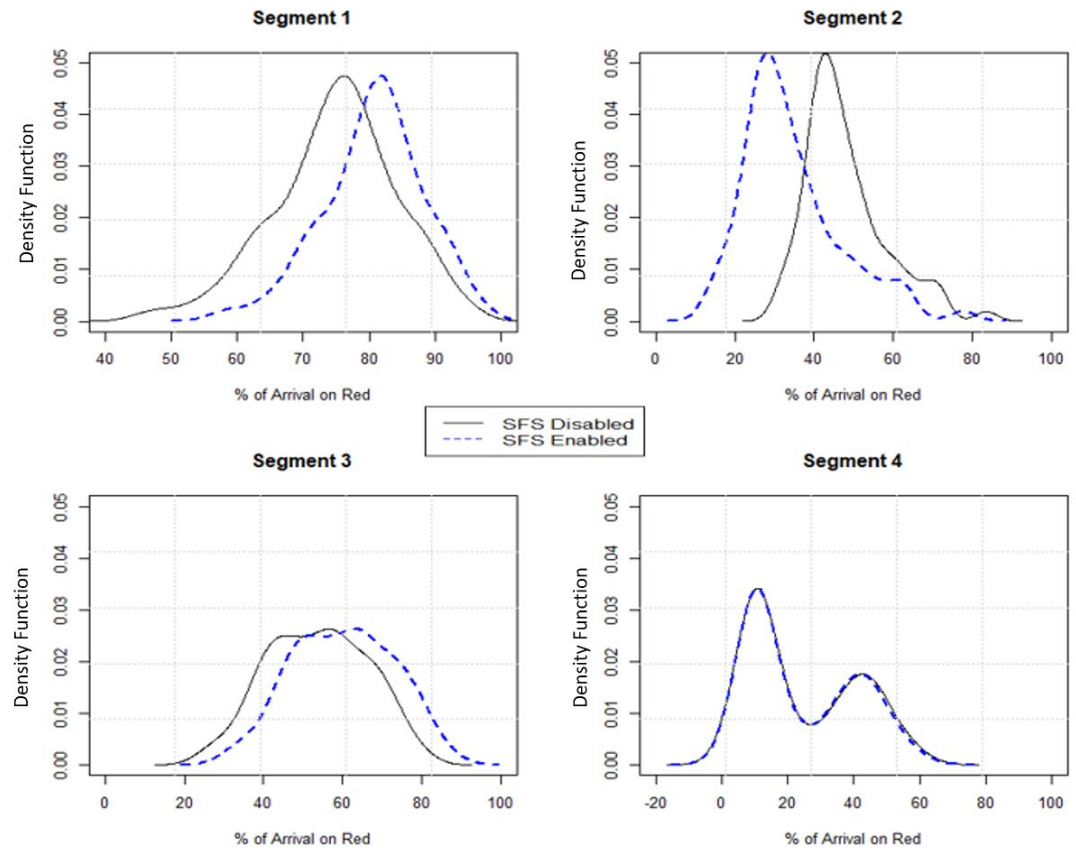

Figure 2.3: Density plot for arrivals on red; morning peak hours

The summary of hypotheses for intersection delay and split failure is provided in Table 2.5. The intersection delay and split failure were collected for all the movements. Therefore, the results were separated for through and left-turn movements. 
Table 2.5: Hypothesis Tests for Split Failure and Intersection Delay

\begin{tabular}{|c|c|c|c|c|c|c|}
\hline & Friedman Test & 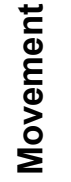 & Period & $\begin{array}{c}\text { Chi- } \\
\text { Square } \\
\left(X^{2}\right)\end{array}$ & $\begin{array}{c}\text { P- } \\
\text { Value }\end{array}$ & Decision* \\
\hline \multirow{6}{*}{ Mean } & \multirow{6}{*}{$\begin{array}{c}H_{0}: \mu_{S F O N}^{S i}=\mu_{S F O F F}^{S i} \\
H_{a}=\text { for at least one segment, the mean } \\
\text { split failure before and after disabling the } \\
\text { SFS is different }\end{array}$} & \multirow{3}{*}{$\begin{array}{l}\text { 동 } \\
\text { 을 } \\
\stackrel{ }{F}\end{array}$} & $\begin{array}{l}\text { AM- } \\
\text { Peak }\end{array}$ & 5.4 & 0.14 & $x$ \\
\hline & & & $\begin{array}{l}\text { PM- } \\
\text { Peak }\end{array}$ & 6 & 0.11 & $x$ \\
\hline & & & $\begin{array}{c}\text { Off- } \\
\text { Peak }\end{array}$ & 6 & 0.11 & $x$ \\
\hline & & \multirow{3}{*}{ 䨔 } & $\begin{array}{l}\text { AM- } \\
\text { Peak }\end{array}$ & 6 & 0.11 & $x$ \\
\hline & & & $\begin{array}{l}\text { PM- } \\
\text { Peak }\end{array}$ & 6 & 0.11 & $x$ \\
\hline & & & $\begin{array}{c}\text { Off- } \\
\text { Peak }\end{array}$ & 6 & 0.11 & $x$ \\
\hline \multirow{6}{*}{ Variance } & \multirow{6}{*}{$\begin{array}{c}H_{0}: \sigma_{S F O N}^{2 S i}=\sigma_{S F}^{2 S i} \\
H_{a}=\text { for at least one segment, the variance } \\
\text { of split failure before and after disabling } \\
\text { the SFS is different }\end{array}$} & \multirow{3}{*}{$\begin{array}{l}\frac{c}{0} \\
\stackrel{\partial}{\frac{0}{E}} \\
\text { F }\end{array}$} & $\begin{array}{l}\text { AM- } \\
\text { Peak }\end{array}$ & 5.4 & 0.14 & $x$ \\
\hline & & & $\begin{array}{l}\text { PM- } \\
\text { Peak }\end{array}$ & 6 & 0.11 & $x$ \\
\hline & & & $\begin{array}{c}\text { Off- } \\
\text { Peak }\end{array}$ & 5.4 & 0.14 & $x$ \\
\hline & & \multirow{3}{*}{$\stackrel{\frac{\pi}{0}}{\unlhd}$} & $\begin{array}{l}\text { AM- } \\
\text { Peak }\end{array}$ & 6 & 0.11 & $x$ \\
\hline & & & $\begin{array}{l}\text { PM- } \\
\text { Peak }\end{array}$ & 6 & 0.11 & $x$ \\
\hline & & & $\begin{array}{c}\text { Off- } \\
\text { Peak }\end{array}$ & 6 & 0.11 & $x$ \\
\hline \multirow{6}{*}{ Mean } & \multirow{6}{*}{$\begin{array}{c}H_{0}: \mu_{D e_{O N}}^{S i}=\mu_{D e_{O F F}}^{S i} \\
H_{a}=\text { for at least one segment, the mean } \\
\text { delay before and after disabling the SFS } \\
\text { is different }\end{array}$} & \multirow{3}{*}{$\begin{array}{l}\text { 동 } \\
\stackrel{5}{0} \\
\stackrel{ }{E} \\
\vdash\end{array}$} & $\begin{array}{l}\text { AM- } \\
\text { Peak }\end{array}$ & 6 & 0.11 & $x$ \\
\hline & & & $\begin{array}{l}\text { PM- } \\
\text { Peak }\end{array}$ & 6 & 0.11 & $x$ \\
\hline & & & $\begin{array}{c}\text { Off- } \\
\text { Peak }\end{array}$ & 6 & 0.11 & $x$ \\
\hline & & \multirow{3}{*}{$\stackrel{\frac{\omega}{0}}{a}$} & $\begin{array}{l}\text { AM- } \\
\text { Peak }\end{array}$ & 6 & 0.11 & $x$ \\
\hline & & & $\begin{array}{l}\text { PM- } \\
\text { Peak }\end{array}$ & 6 & 0.11 & $x$ \\
\hline & & & $\begin{array}{l}\text { Off- } \\
\text { Peak }\end{array}$ & 6 & 0.11 & $x$ \\
\hline \multirow{4}{*}{ Variance } & \multirow{4}{*}{$\begin{array}{c}H_{0}: \sigma_{D e_{O N}^{2}}^{2 S i}=\sigma_{D e_{O F F}^{2}}^{2 S i} \\
H_{a}=\text { for at least one segment, the variance } \\
\text { of delay before and after disabling the } \\
\text { SFS is different }\end{array}$} & \multirow{3}{*}{$\begin{array}{l}\frac{c}{D} \\
\text { 을 } \\
\stackrel{F}{\vdash}\end{array}$} & $\begin{array}{l}\text { AM- } \\
\text { Peak }\end{array}$ & 5.4 & 0.14 & $x$ \\
\hline & & & $\begin{array}{l}\text { PM- } \\
\text { Peak }\end{array}$ & 5.4 & 0.14 & $x$ \\
\hline & & & $\begin{array}{c}\text { Off- } \\
\text { Peak }\end{array}$ & 6 & 0.11 & $x$ \\
\hline & & $\stackrel{+\infty}{\Delta}$ & $\begin{array}{l}\text { AM- } \\
\text { Peak }\end{array}$ & 6 & 0.11 & $x$ \\
\hline
\end{tabular}




\begin{tabular}{|l|l|l|c|c|c|c|}
\hline & & & $\begin{array}{c}\text { PM- } \\
\text { Peak }\end{array}$ & 6 & 0.11 & $X$ \\
\cline { 3 - 6 } & $\begin{array}{c}\text { Off- } \\
\text { Peak }\end{array}$ & 6 & 0.11 & $X$ \\
\hline
\end{tabular}

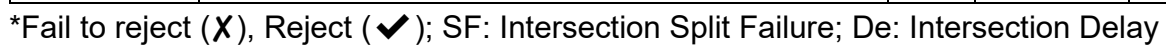

The results from Table 2.5 indicate that, at a significance level of 0.05 , there is not sufficient evidence to reject the null hypothesis. In other words, based on these results, the existence of SFS does not have a statistically significant impact on either the split failure or intersection delay.

Overall, based on the results from the statistical tests, with 95\% confidence, we were not able to point out any significant effect caused by SFS on the signal performance measures, and consequently, the arterial mobility at the intersection level. However, further, inspection is required to point out if enabling the SFS will affect arterial mobility at the link level.

\subsection{IMPACT OF SFS ON ARTERIAL LINKS}

To evaluate the potential impact of SFS on arterial links, the performance measure used was the link speed. Statistical comparisons between link speed before and after disabling the SFS were performed as appropriate. Tables 2.6 and 2.7 demonstrate the average link speed and $85^{\text {th }}$ percentile of link speed, respectively, during the times were SFS were enabled and disabled.

Table 2.6: Link Speed and 85th Percentile Link Speed-Weekday

\begin{tabular}{|c|c|c|c|c|c|c|c|c|c|}
\hline \multicolumn{10}{|c|}{ Weekday } \\
\hline \multicolumn{6}{|c|}{ Link Speed (mph) } & \multicolumn{4}{|c|}{$85^{\text {th }}$ percentile link speed $(\mathrm{mph})^{* *}$} \\
\hline Site & $\begin{array}{c}\text { Sample } \\
\text { Size }\end{array}$ & Disabled & Enabled & $\begin{array}{c}P_{-} \\
\text {Value }\end{array}$ & Decision* & Disabled & Enabled & P-Value & Decision* \\
\hline 1 & 970 & 28.2 & 27.3 & $<0.05$ & $\checkmark$ & 32.9 & 29.1 & $<0.05$ & $\checkmark$ \\
\hline 2 & 970 & 34.2 & 33.1 & $<0.05$ & $\checkmark$ & 38.1 & 37.2 & 0.01 & $\checkmark$ \\
\hline 3 & 970 & 35.8 & 34.2 & $<0.05$ & $\checkmark$ & 38.7 & 37.8 & $<0.05$ & $\checkmark$ \\
\hline 4 & 970 & 34.9 & 34.4 & 0.6250 & $x$ & 40.2 & 39.5 & 0.09 & $x$ \\
\hline
\end{tabular}

${ }^{*}$ Fail to reject $(\boldsymbol{X})$, Reject $(\checkmark){ }^{* *}$ To compare the 85th percentile of link speed permutation test is used.

Table 2.7: Link Speed And 85th Percentile Link Speed-Weekend

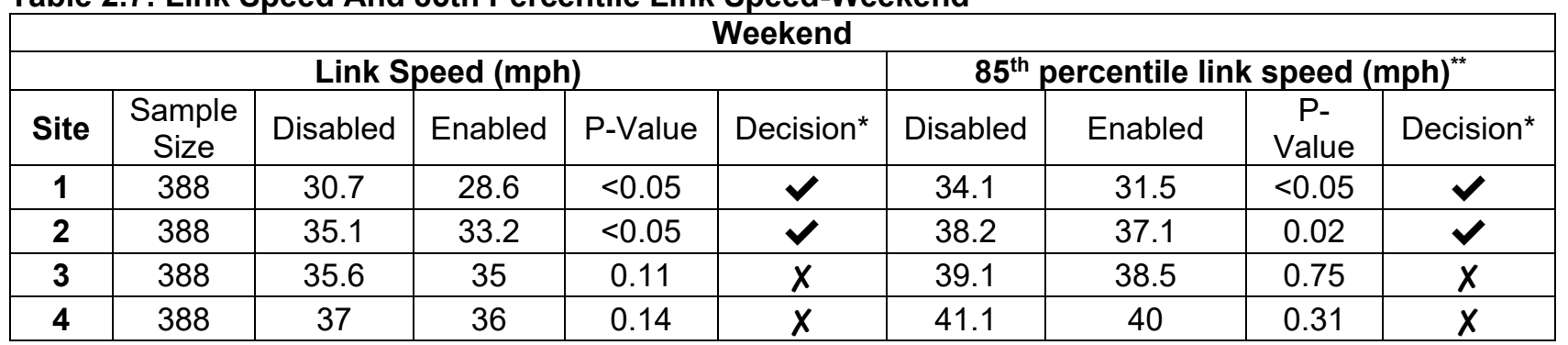

${ }^{*}$ Fail to reject $(\boldsymbol{X})$, Reject $(\checkmark){ }^{* *}$ To compare the $85^{\text {th }}$ percentile of link speed permutation test is used.

Tables 2.6 and 2.7 show a statistically significant increase at the level of $p=0.05$ in the link speed and $85^{\text {th }}$ percentile of link speed after disabling the SFS. Overall, after disabling the SFS link speed increased at three out of four sites during the weekday and 
two out of four sites during the weekend. It is worthwhile to mention that, intuitively, the extent of the impact of SFS on driver operating speed is varied, and it is expected to be a function of their running speed. That is, drivers with a higher running speed tend to reduce their speed at a higher rate after observing their speed on the SFS display.

Speed variability is another factor that could directly impact arterial mobility and signal performance (K. M. Kockelman \& Ma, 2007; Xuesong Wang et al., 2018). Therefore, it is also essential to evaluate the potential impact of SFS on link-speed variation. Figure 2.4 illustrates the probability density plot and box plot of the link speed at each segment before and after disabling the SFS. The standard deviations of the speed distribution before and after disabling the SFS are shown in the parenthesis.

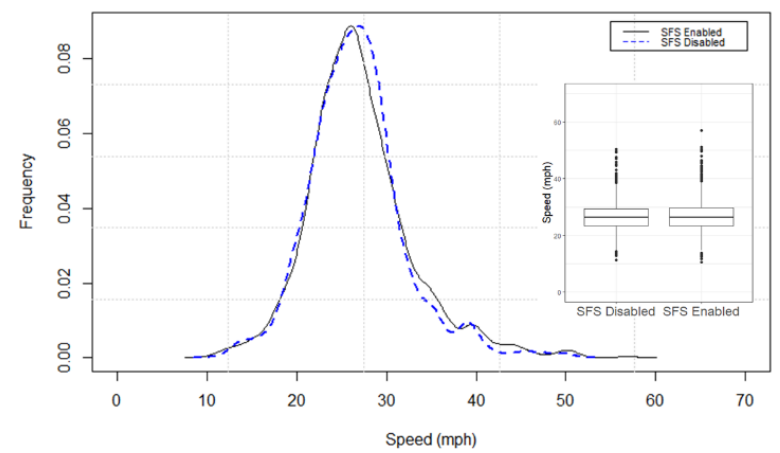

Segment 1: from N Shannon Rd to N La Cholla Blvd.

$\left(S D_{S F S-\text { enabled }}=5.9 \mathrm{mph} ; S D_{S F S-\text { disabled }}=5.3\right.$ $\mathrm{mph})$

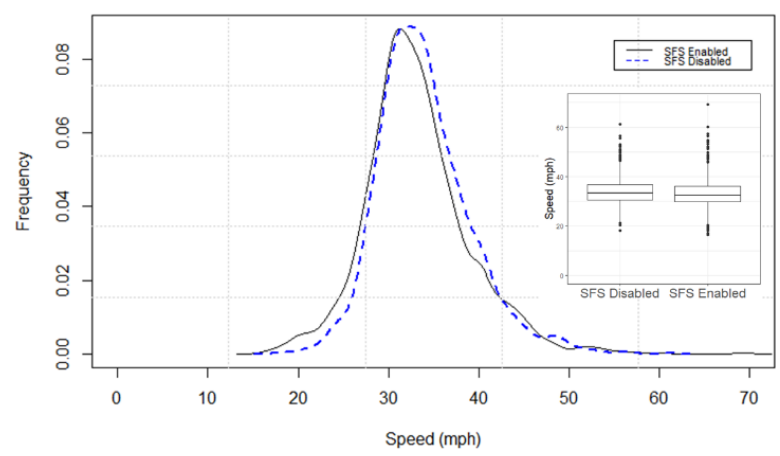

Segment 3: from N La Canada Dr. to N La Cholla Blvd.

$\left(S D_{S F S-\text { enabled }}=5.8 \mathrm{mph} ; S D_{S F S-\text { disabled }}=5.2\right.$ $\mathrm{mph})$

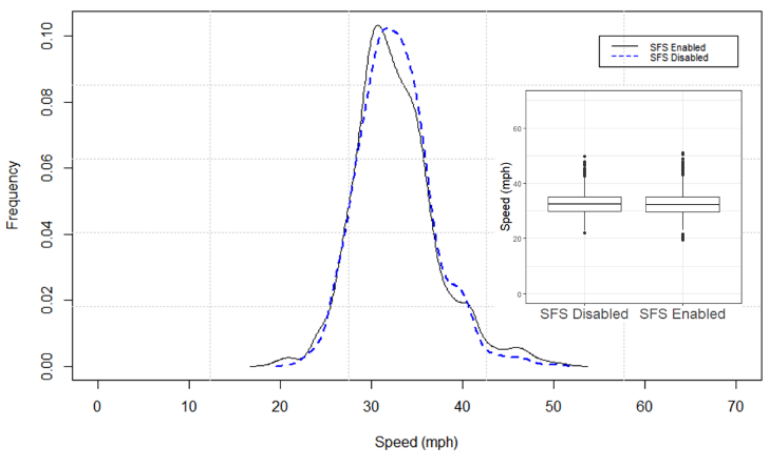

Segment 2: from N La Cholla Blvd. to N La Canada Dr.

$\left(S D_{S F S-\text { enabled }}=4.5 \mathrm{mph} ; S D_{S F S-\text { disabled }}=\right.$ $4.01 \mathrm{mph}$

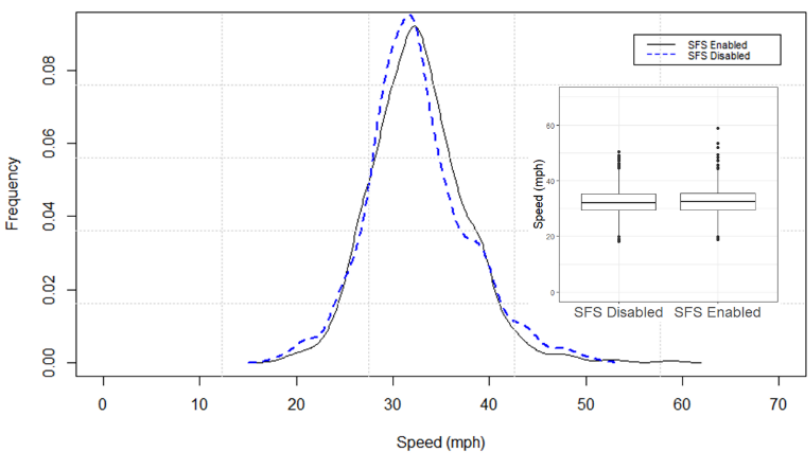

Segment 4: from N La Cholla Blvd. to N Shannon $\mathrm{Rd}$.

$\left(S D_{S F S-\text { enabled }}=4.9 \mathrm{mph} ; S D_{S F S-\text { disabled }}=5.1\right.$ $\mathrm{mph})$

Figure 2.4: Speed density distribution and speed box plot

For all the segments (except segment 4), link speed before and after disabling the SFS has a similar peak. However, the mean value has been shifted and increased after disabling the SFS. In addition, for all the segments (except segment 4), the speed 
variation decreased by disabling the SFS. Based on the results of the statistical test for equality of the variance, the difference of link speed variances before and after disabling the SFS were statistically significant for all the segments at a level of $p=0.05$, except segment $4(p$-value $=0.08)$.

Speeding is a general issue in traffic studies and is usually a contributing factor to both crash severity and frequency. In this study, driver speed change behavior models were estimated to understand drivers' behavior while approaching SFS. These behavior models relate the link speed before and after disabling the SFS. To develop the driver speed change behavior model, linear mixed models (LMM) were formulated between the link speed before and after disabling the SFS.

LMM models are an extension of simple linear models that allow the users to include both fixed and random effects into the modeling procedure (Fox, 2015). The mixed models are usually used when modeling the data from multiple levels (in our case, the data are collected from multiple sites). In addition to the fixed-effect terms in a simple linear model, the mixed model incorporates several random-effect terms. The randomeffect terms made the mixed models appropriate for modeling the data that are collected hierarchically. In theory, the linear mixed models are formulated in Equation (2-4) (West et al., 2014):

$$
\boldsymbol{y}=X \boldsymbol{\beta}+Z \boldsymbol{c}+\boldsymbol{\epsilon}
$$

where $\mathrm{y}$ is the vector of outcomes, $\mathrm{X}$ is the design matrix of fixed-effect terms, $\beta$ is the vector of fixed-effect coefficients. $Z$ is the matrix of random-effect terms, $c$ is the vector of random-effect terms and $\epsilon$ is the vector of residuals.

The design matrix of fixed-effect terms $(X)$ consists of two columns: intercept and $y_{t, j}^{o f f}$; where $y_{t, j}^{o f f}$ is the link speed at the time of $t$ for the $j^{\text {th }}$ site, when the SFS is disabled. The vector of outcomes $(Y)$ consists of one column, $y_{t, j}^{o n}$; where $y_{t, j}^{o n}$ is the link speed at time $t$ for the $j^{\text {th }}$ site, when the SFS is enabled. $\beta_{0}, \beta_{1}$ are the coefficients of the fixedeffect terms. In the design matrix of random-effect terms $(Z)$, each column represents one site and each row represents one observation. If the observation belongs to the site in that column, $z_{t, j}=1$ otherwise, $z_{t, j}=0$. Equation (2-4) can be reformulated as below:

$\left[\begin{array}{c}y_{1,1}^{o n} \\ y_{1,2}^{o n} \\ \vdots \\ y_{4, N}^{\text {on }}\end{array}\right]_{N \times 1}=\left[\begin{array}{cc}\text { Intercept } & y_{1,1}^{\text {off }} \\ 1 & y_{1,2}^{\text {off }} \\ \vdots & \vdots \\ 1 & y_{4, N}^{\text {off }}\end{array}\right]_{N \times 2} \quad\left[\begin{array}{l}\beta_{0} \\ \beta_{1}\end{array}\right]_{2 \times 1}+\left[\begin{array}{cccc}z_{1,1} & z_{2,1} & z_{3,1} & z_{4,1} \\ z_{1,2} & z_{2,2} & z_{3,2} & z_{4,2} \\ \vdots & \vdots & \vdots & \vdots \\ z_{1, N} & z_{2, N} & z_{3, N} & z_{4, N}\end{array}\right]_{N \times 4}\left[\begin{array}{c}c_{1} \\ c_{2} \\ c_{3} \\ c_{4}\end{array}\right]_{4 \times 1}+\left[\begin{array}{c}\varepsilon_{1} \\ \varepsilon_{2} \\ \vdots \\ \varepsilon_{N}\end{array}\right]_{1 \times N}$

where $c_{1}$ to $c_{4}$ are the random effects and $\epsilon_{i}$ is the vector of residual error. In this study, $\mathrm{N}$ is the total number of link speed observations collected during the four weeks (May 28-June 25, 2018) of the study period. The total number of random-effect terms is equal to the number of study sites $(j=4)$, which accounts for variations unique to each segment. The notation of the model can be reformulated into a system of equations as: 


$$
\begin{gathered}
y_{t, j}^{o n}=\beta^{\prime}{ }_{0}+\beta_{1} y_{t, j}^{o f f}+\epsilon \\
\beta^{\prime}{ }_{0}=c_{i}+\beta_{0} \\
\beta^{\prime}{ }_{1}=\beta_{1}
\end{gathered}
$$

The coefficients in Equation 6-a $\left(\beta^{\prime}{ }_{0}\right.$ and $\left.\beta^{\prime}{ }_{1}\right)$ can be represented as the combination of the fixed-effect terms $\left(\beta_{0}\right.$ and $\left.\beta_{1}\right)$ and random-effect terms $\left(c_{i}\right)$. For this study, the random-effect terms are only included in the intercept. Substituting the (2-6) \& (2-7) equations into (2-8) equation, the final mixed model will be developed as:

$$
y_{t, j}^{o n}=\beta_{1} y_{t, j}^{o f f}+\left(c_{i}+\beta_{0}\right)+\varepsilon
$$

To develop the final model (Equation 3-9), maximum likelihood estimation is used to estimate the regression coefficients. The random-effect terms $\left(c_{i}\right)$ are usually assumed to follow normal distributions with a mean of zero and variance of $G ; \mathrm{G}$ is the covariance

\begin{tabular}{|c|c|c|c|c|c|c|c|}
\hline LMM & \# of Observation & AIC & LL & Coefficient & Estimate & P-Value & Function \\
\hline \multirow{2}{*}{ Weekday } & \multirow{2}{*}{3,880} & \multirow{2}{*}{20,812} & \multirow{2}{*}{$-10,402$} & $\beta_{0}^{\prime}$ & 22.55 & 1.16 & \multirow{2}{*}{$\begin{array}{c}y^{\text {on }}=22.55+0.3 \\
y^{\text {off }}\end{array}$} \\
\hline & & & & $\beta_{1}^{\prime}$ & 0.3 & 0.01 & \\
\hline \multirow{2}{*}{ Weekend } & \multirow{2}{*}{1,552} & \multirow{2}{*}{$82,28.2$} & \multirow{2}{*}{$-4,060.1$} & $\beta_{0}^{\prime}$ & 23.79 & 1.02 & \multirow{2}{*}{$\begin{array}{c}y^{o n}=23.79+0.3 \\
1 y^{o f f}\end{array}$} \\
\hline & & & & $\beta_{1}^{\prime}$ & 0.31 & 0.02 & \\
\hline
\end{tabular}
matrix of random effects. Table 2.8 summarizes the results of fitting mixed models on the observation.

Table 2.8: Results of Fitted Linear Mixed Models

$y^{o n}=$ speed when SFS is enabled, $y^{o f f}=$ speed when SFS is disabled; LL=log-likelihood

The models developed in Table 2.8 relate the link speed when the SFS is enabled (y) to the link speed when SFS is disabled (x). Based on Equation 6-a, in the mixed models, the random-effect terms are complemented to the coefficients of the fixed-effect terms. The $p$-value for the estimated coefficients shows both variables are significant to the mixed model. To demonstrate the effectiveness of the speed feedback sign based on the value of the link speed, a visualization relating the effectiveness versus different link speed is illustrated in Figure 2.5. A negative value for the effectiveness shows enabling the SFS will make the drivers increase their speed (increase in link speed) after observing their speed. While a positive value for effectiveness shows enabling the SFS will make the drivers decrease their speed (reduction in link speed) after observing their speed. The models developed in Table 2.8 are used to find the effectiveness values. 


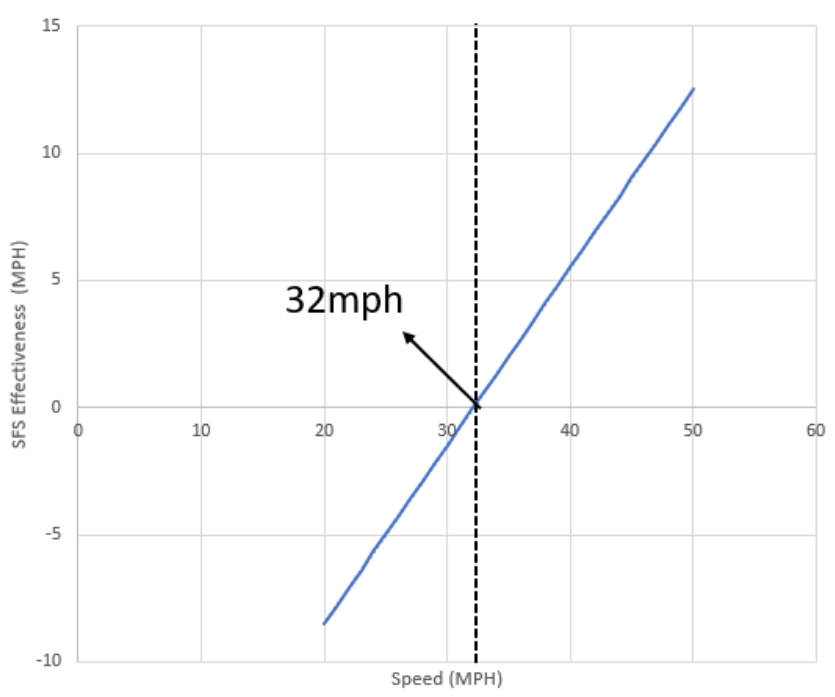

(a)

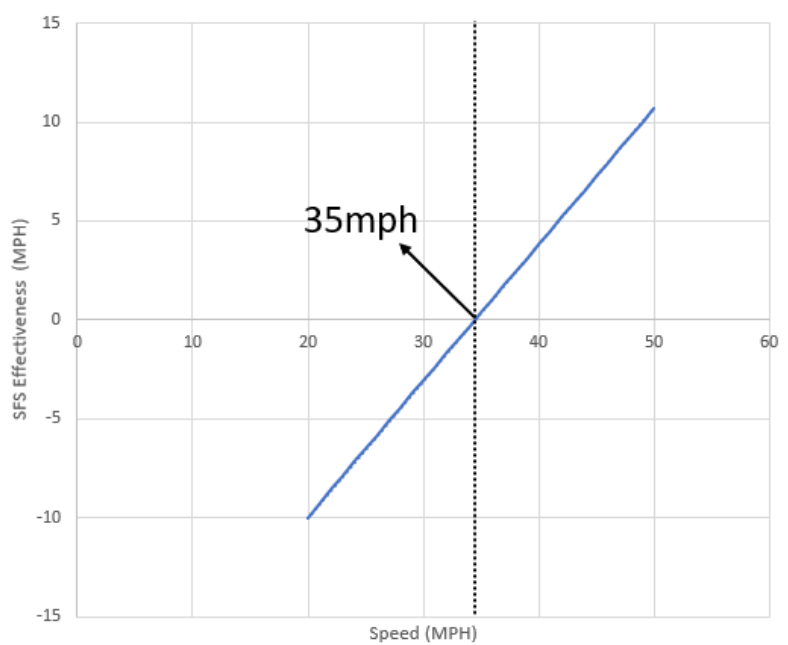

(b)

Figure 2.5: Effectiveness of SFS; A) weekday, B) weekend

The following findings could be observed from the models developed in Table 8 and the SFS effectiveness plot in Figure 2.5:

- Analyzing the speed change behavior model and the SFS effectiveness plot for the weekday shows for link speeds equal or lower than $32 \mathrm{mph}$, the drivers might speed up after they are informed of their speed by the SFS. However, with link speeds equal to or more than $32 \mathrm{mph}$, the drivers might slow down after they are informed of their speed by the SFS. Therefore, the link speed of $32 \mathrm{mph}$ could be assumed as the breakpoint at which the SFS drivers behave differently while noticing the SFS. 
- Similar results could be concluded by analyzing the model and the SFS effectiveness of the weekend. For link speeds equal or lower than $35 \mathrm{mph}$, the drivers might speed up after they are informed of their speed by the SFS. However, with link speeds equal or more than $35 \mathrm{mph}$, the drivers might slow down after they are informed of their speed by the SFS.

- For both models (weekend and weekday), the speed reduction rate is higher for the drivers operating at higher speeds compared to drivers operating at a lower speed.

Further investigation on the relationship between the link-level mobility and safety will shed more light on the potential impact of SFS on arterial safety. The next section will provide further details on the relationship between speed and crash frequency and severity.

\subsection{CONNECTING MOBILITY TO SAFETY}

Measuring the safety impact of SFS requires a massive amount of crash data (Hallmark et al., 2015). However, this type of historical crash data is not always available or sufficient for transportation agencies to conduct robust safety studies. One way to evaluate the potential improvement of an arterial after installing SFS is to extrapolate mobility measures into the safety ones. The advantage of using mobility information to estimate safety benefit is that no historical crash data is required.

The relationship between mobility and safety could be explored in the kinetic energy equation. The kinetic energy equation shows that higher speeds will lead to higher kinetic energy ( $E \sim v^{2}$; E: kinetic energy and v: speed), and consequently leading to more severe crashes. Nilsson (1982) showed that the expected number of injury crashes due to the change in the average speed could be estimated using Equation (210).

$$
N_{2}=N_{1}\left(\frac{S_{2}}{S_{1}}\right)^{2}
$$

where $N_{1}$ and $N_{2}$ are the total number of severe crashes before and after the change in the average speed, and $S_{1}$ and $S_{2}$ are the former and new average speed. A similar formulation was also reported (K. Kockelman et al., 2006; Malyshkina \& Mannering, 2008).

In this study, to estimate the benefit in dollar value associated with the reduction in severe crashes (average economic cost per one severe injury crash is approximately $\$ 1$ million (Blincoe et al., 2015)), crash count for our study corridor was obtained from the Pima Association of Governments (PAG). Based on the information provided by PAG, the total number of four severe crashes occurred before implementing the SFS in 2015. Using the model developed in Table 2.8, the link speed before and after disabling the SFS were estimated. Then, based on Equation 8 the percentage of severe crashes reduction was estimated. Table 2.9 shows the percentage of severe crash reduction 
due to the implementation of SFS, and the benefit in dollars associated with this reduction.

Table 2.9: Quantification of Safety Benefit

\begin{tabular}{|c|c|c|c|c|}
\hline & $\begin{array}{c}\text { Link Speed } \\
\left(S F S_{\text {disabled }}\right) \\
\text { mph }\end{array}$ & $\begin{array}{c}\text { Link Speed } \\
\left(\text { SFS } S_{\text {enabled }}\right) \\
\text { mph }\end{array}$ & $\begin{array}{l}\text { Percentage of } \\
\text { severe crash } \\
\text { reduction (\%) }\end{array}$ & $\begin{array}{l}\text { Benefit in dollar value per } \\
\text { year associated with a } \\
\text { reduction in the severe } \\
\text { crash for the study } \\
\text { corridor }\end{array}$ \\
\hline \multirow{3}{*}{$\begin{array}{l}\frac{\lambda}{0} \\
\frac{0}{d} \\
\stackrel{d}{3}\end{array}$} & 45 & 36 & 36 & $\$ 1,008,000$ \\
\hline & 40 & 34.5 & 25.6 & $\$ 737,280$ \\
\hline & 35 & 33 & 11.1 & $\$ 319,680$ \\
\hline \multirow{3}{*}{ 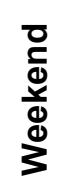 } & 45 & 37.7 & 29.8 & $\$ 357,600$ \\
\hline & 40 & 36.2 & 18.1 & $\$ 217,200$ \\
\hline & 35 & 34.6 & 8.5 & $\$ 102,000$ \\
\hline
\end{tabular}

\subsection{CONCLUSION}

To evaluate the potential impact of SFS on arterial mobility and safety, an observational before-after study was conducted on an arterial road in Tucson, AZ. The arterial mobility was evaluated at intersection and link levels. In addition, the effect of SFS on the dispersion of operating speed was also investigated by developing a speed change behavior model. Last, the safety benefit of an active SFS were quantified at the linkspeed level using the proposed driver speed change model.

To evaluate the arterial mobility at the intersection level, three performance measures, including percent of arrival on red, intersection delay, and split failures, were used. The results showed no statistically significant differences in either mean or variance of the respective measures before and after disabling the SFS. To evaluate arterial mobility at the link level, link speed was selected as the performance measure. Statistical comparisons between link speed before and after disabling the SFS were performed as appropriate. The results showed that at three out of four sites, the reduction in the link speed was significant during the times the SFS were enabled. In addition, it was found that the impact of SFS on drivers' behavior is a function of their approaching speed. Drivers within specific speed bins behave differently after they were informed of their speed by the SFS. Finally, the benefit in dollar value per year associated with a reduction in severe crashes on the study arterial with active SFS showed promising safety enhancement. 


\subsection{IMPACT OF SPEED MANAGEMENT STRATEGIES ON CONNECTED CORRIDORS}

This chapter explores the impact of a speed management strategy on a connected corridor in Salt Lake City, UT. More specifically, this chapter discusses the impacts of the specific speed management, signal retiming and coordination on transit signal priority (TSP). This chapter is prepared based on a published journal article (Q. Wang et al., 2020).

\subsection{BACKGROUND}

With the accelerated development of wireless technology, connected vehicle $(\mathrm{CV})$ is believed to be one of the promising technological advances for the automotive revolution. A series of emerging technologies, including wireless communication, global position system navigating, onboard unit processing, etc. are integrated to construct a communicated system. With the application of the system, vehicles are capable of communicating with each other or with roadside infrastructure, enabling vehicles to operate in a smarter way. Therefore, the safety, mobility, and environmental influence of the transportation system can be boosted. Inspired by the benefits, UDOT has started to launch a study to deploy a fully dedicated short-range communication (DSRC) corridor. As an initial application, UDOT equipped several transit vehicles with onboard processors and GPS systems to enable them to communicate with traffic signals (V2I). Such V2I communication is able to provide intelligent TSP to buses. More specifically, if the bus is behind its schedule, it will send requested TSP information to traffic signals and when it drives into the DSRC communication range of intersections and TSP control algorithms will be activated.

Although TSP is one of the promising ways to reduce bus delays at intersections, improve transit operational reliability, and consequently increase transit ridership with improved service, the effectiveness of TSP is subject to various factors, such as bus schedule, signal timing plan, passenger flows, etc. Considering this, UDOT adopted a speed management strategy - signal coordination and retiming - to improve the effectiveness of TSP. In detail, UDOT implemented signal coordination along this DSRC corridor and applied several signal timing plans with the aim of maximizing the benefits of TSP. Therefore, this chapter aims to evaluate the performance of TSP between two signal coordination plans. 


\subsection{DEPLOYMENT SITE DESCRIPTION}

When UDOT selected a corridor to install the CV-based TSP system, three standards were considered: 1) an urban arterial which has one bus route and buses along this route often experience delays; 2 ) traffic signals along this corridor are managed by UDOT; and 3) various traffic conditions occur along this arterial. Based on the above criteria, UDOT selected Redwood Road as the ideal corridor. Redwood Road is a northsouth arterial located in the west of downtown in Salt Lake City. A segment of this road, from 400 South to 8040 South, was selected to deploy the related DSRC corridor. This corridor is approximately 11 miles long with 35 signalized intersections, shown in Figure 3.1. This corridor includes a variety of types of land use, including commercial districts, industrial areas, residential areas, a high school, and a community college. One regular bus line, bus 217 , travels through this corridor. During the early morning and late evening, this bus operates with a 30-minutes headway. After 9:00 p.m., the headway is 60 minutes. For the rest of the day, the headway is 15 minutes.

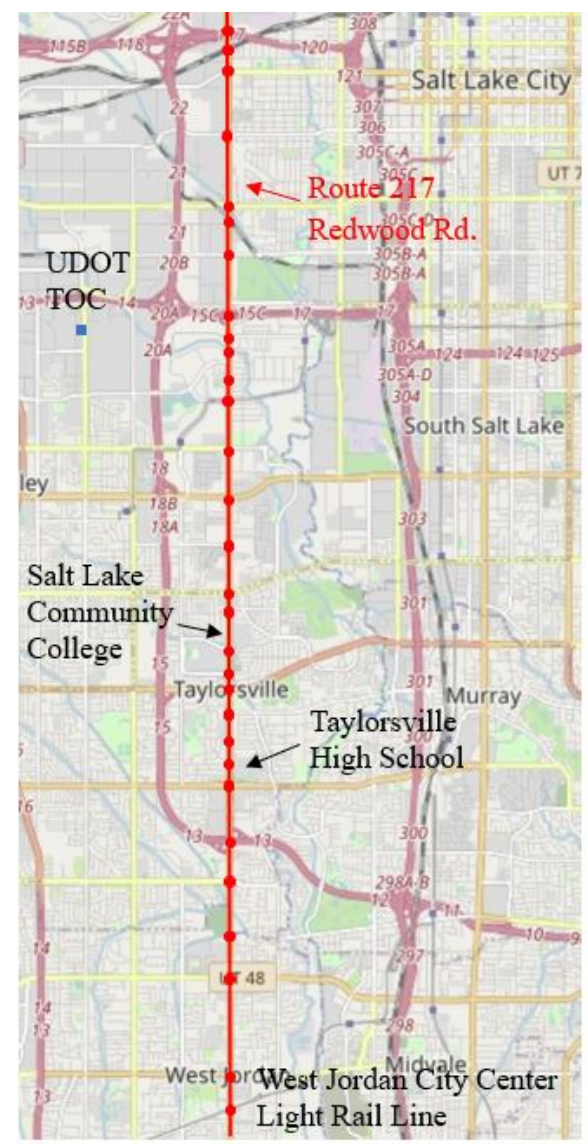

Figure 3.1: DSRC corridor for transit signal priority in Salt Lake City 


\section{Application Hardware}

Nowadays, the commonly adopted technology supporting the communication between vehicle to vehicle (V2V) or V2I is DSRC. DSRC is a one-way or two-way wireless communication channel specifically designed for automotive use. In the UDOT deployment, 30 intersections were picked up to install DSRC roadside units (RSUs) and nine UTA buses were selected to equip with onboard units (OBUs). Those RSUs and OBUs are purchased from four vendors, including Savari, Arada, Cohda, and Lear. According to the Society of Automotive Engineers, the broadcasted message between RSUs and OBUs can be categorized into four types: Basic Safety Message (BSM), SPaT, MAP Message (MAP), and Signal Request Message (SRM), Signal Status Message (SSM) (Draft, 2006). The detailed introduction of the message is shown in Table 3.1.

Table 3.1: Information of Broadcasted Messages through V2I

\begin{tabular}{|c|c|c|}
\hline Message type & Function & Message information \\
\hline BSM & $\begin{array}{c}\text { Information related to the real-time } \\
\text { operating status of vehicles }\end{array}$ & $\begin{array}{c}\text { Vehicle positions; speed; heading, } \\
\text { brake status; windshield wiper status; } \\
\text { headlight status }\end{array}$ \\
\hline SPaT & $\begin{array}{c}\text { Information about intersection and the } \\
\text { current status of traffic signals }\end{array}$ & $\begin{array}{c}\text { Intersection ID; signal status; active } \\
\text { priority and preemption state data }\end{array}$ \\
\hline MAP & $\begin{array}{c}\text { The geometric information of the } \\
\text { intersection defined at the lane level }\end{array}$ & $\begin{array}{c}\text { Intersection ID; Refpoint; lane } \\
\text { number; lane width }\end{array}$ \\
\hline SRM & $\begin{array}{c}\text { Information is sent by several types of } \\
\text { vehicles (e.g., transit) to request signal } \\
\text { priority }\end{array}$ & $\begin{array}{c}\text { Vehicle type; time of service; and } \\
\text { type of request }\end{array}$ \\
\hline SSM & $\begin{array}{c}\text { Information to reply to a service request } \\
\text { sent by the SRM message }\end{array}$ & $\begin{array}{c}\text { All active priority and preemption } \\
\text { states; all pending requests; the } \\
\text { signal state }\end{array}$ \\
\hline
\end{tabular}

Considering the four vendors applied different methods to manage the transmitted information, BeagleBone Black industrial-grade Linux boards with $1 \mathrm{GHz}$ CPU with $4 \mathrm{~GB}$ of flash memory were selected by UDOT to install to deal with the received incompatible information (Leonard et al., 2019).

\section{Application Software}

Multi-Modal Intelligent Traffic Signal System (MMITSS), developed for the Connected Vehicle Pooled Fund Study by the University of Arizona and the University of California PATH program, was selected by UDOT as the software to support TSP application. MMITSS is a comprehensive system that is capable of accommodating TSP, emergency vehicle preemption, and pedestrian movements to maximize network performance. In the Utah initial deployment, only TSP was selected for the test. MMITSS enables agencies to implement TSP based on several factors. Bus arrival time and bus occupancy are the factors considered in this deployment. More specifically, if the bus occupancy is more than $20 \%$ when the bus arrives at a bus station behind its scheduled time for more than five minutes, priority will be granted to the bus to let it get back on schedule. The applied software is called MMITSS-Utah since various 
modifications were made for the original MMITSS software to satisfy the operation of the Utah traffic system.

\subsection{DATA DESCRIPTION AND PROCESSING}

\subsubsection{Data Description}

In this study, to evaluate the performance of the implemented speed management strategy, datasets from three distinct sources (DSRC, ATSPM, UTA) were collected, illustrated in Figure 3.2 (Leonard et al., 2019). It can be observed what data are collected from each source and how they join and correlate. The labels on the arrows indicate what fields were used to join records between the datasets. Note that the UTA datasets were used independently of the other datasets. In this research, the data of four months in 2018 (August, September, November, and December) were selected to perform evaluations.

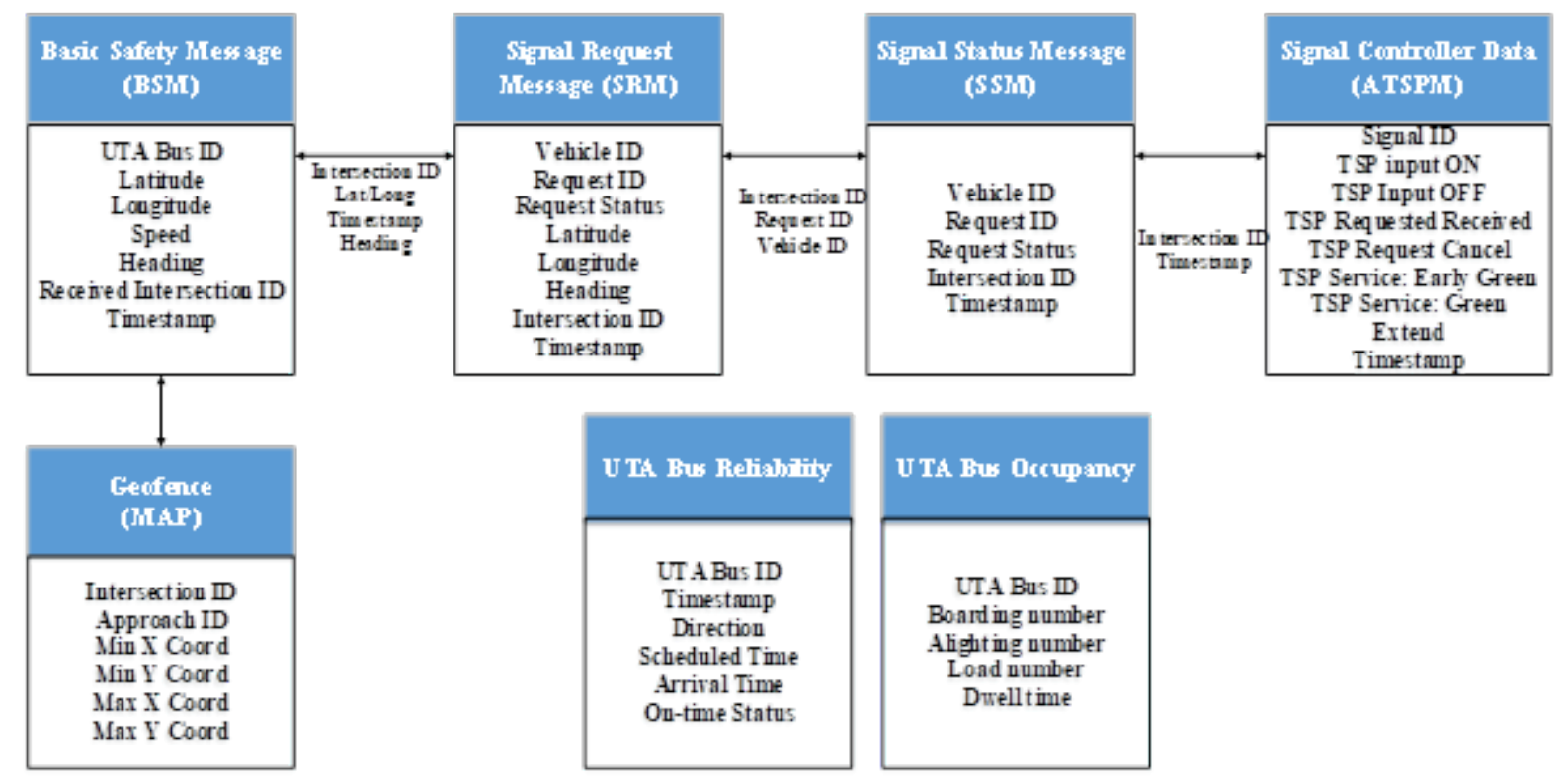

Figure 3.2: Available datasets diagram

\section{DSRC Data}

MAP message, BSM message, SRM message, and SSM message in the above figure belong to DSRC data which were obtained from the system that manages the communication between the buses and the traffic signals. A detailed description of those four types of messages can be found in Table 3.1. 


\section{UTA Data}

Two types of datasets, reliability dataset and occupancy dataset, were collected from UTA. Each record in the reliability dataset includes the timestamp, bus ID, driving direction, the actual and scheduled arrival time to bus stops, and the bus status ("Critical early," "Early," "On time," "Late," and "Critical Late"). UTA defines these statuses using a five-minute difference and a 15-minute difference between the actual arrival time and scheduled arrival time, shown in Table 3.2. The occupancy database records the number of passengers on the bus, the number of passengers boarding and alighting at each bus station, and the dwell time at each bus station.

Table 3.2: Rules to Define Bus Status at Each Timepoint

\begin{tabular}{|c|c|}
\hline Actual arrival time - Scheduled arrival time (min) & Bus status \\
\hline$(-\infty,-15)$ & Critical Late \\
\hline$(-\mathbf{1 5}, \mathbf{0})$ & Late \\
\hline$(\mathbf{0 , 5})$ & On-Time \\
\hline$(\mathbf{5 , 1 5})$ & Early \\
\hline$(\mathbf{1 5},+\infty)$ & Critical Early \\
\hline
\end{tabular}

\section{ATSPM Data}

ATSPM data provides related traffic signal information which is stored in UDOT's traffic signal system. The data contains the signal ID, the timestamp, the event number, and the event parameter. The event number and the event code can be encoded according to "Indiana Traffic Signal Hi-Resolution Data Logger Enumerations."

\subsubsection{Data Processing}

The collected data requires processing before conducting the assessments. Notably, although the defined communication distance between RSU and OBU is 1,000 feet, this distance can be usually greater in practice. Therefore, on some occasions, the message buses sent to one signal can also be received by other signals. Moreover, a great deal of redundant data will be generated due to the high frequency of data broadcasting, which is every one-tenth of a second. To address these issues, signal ID was used to pair the BSM data, and the Map data and the BSM data are filtered by the maximum and minimum limits set by geofence per intersection. Then the limit, time, and direction filters were used to determine the first and last records for each bus event and to identify the duration of the bus at each signal.

Instead of using local time, all the DSRC data were recorded with Greenwich Mean Time (GMT). As daylight savings occurred during the data collection period, timestamps were required to change to local time based on the changes of six or seven hours according to the date of data collection. BSM datasets and SRM datasets reported driving direction as "heading." "Heading" represents compass bearing which requires to be converted to "northbound." "southbound," "westbound," and "eastbound." Then the 
data with "westbound" and "eastbound" are filtered since the direction of Route 217 is from northbound/southbound to southbound/northbound.

Traffic signals along this DSRC corridor are controlled by two brands of controllers: Intelight MaxTime and Econolite Cobalt. The two types of controllers manage TSP event codes in different ways. For example, the Intelight Controller uses event codes 517 and 518 to denote TSP activation, but the Econolite controller represents TSP activation as codes 113 and 114 . Therefore, these unique event codes need to be converted to TSP Check In, Check Out, and Served.

The number of TSP requested can be obtained from the SRM dataset, and ATSPM datasets can be used to determine whether a requested TSP is served. Hence, the ratio of served TSP for a specific time (e.g., one day) can be determined with the two datasets. However, after reviewing those data, it was found that the date in the two databases was not consistent due to several lost. Therefore, they need to be processed to ensure the date of the two datasets is the same.

\subsection{RESULT ANALYSIS}

\subsubsection{TSP Requested and TSP Served Analysis}

To evaluate the impact that signal coordination exerts on the operation of the TSP system, one key procedure is to make clear how often TSPs are requested and served. This is due to the fact that too many TSP services will exert devastating impacts on road users and too few TSP services will restrict the function of the TSP benefit. Moreover, such a step is also critical to comprehend the change of bus performance before and after signal retiming. Hence, it is necessary to know the number of buses traveling through intersections obtained from the BSM dataset and how many TSP are requested utilizing the SRM dataset. More specifically, buses will transmit multiple messages when they travel through a DSRC-equipped intersection and they are restored in the BSM dataset. In this dataset, multiple continuous records can be grouped into a single event, which denotes one bus travels through this intersection. Based on this principle, the total number of bus trips at each intersection can be determined by aggregating the grouped bus events. The number of requests can be simply obtained from the SRM dataset. Therefore, the TSP-requested ratio can be calculated by comparing these two values. How many requested TSP are served can be identified by the ATSPM dataset. When signal controllers receive a requested TSP, it will record this event and it will be designated as TSP served if extra time is provided to buses. Then the TSP-served ratio can be calculated. Figure 3.3 (a) and (b) show the percentage of TSP requested and served at each intersection before and after signal retiming. The blue area denotes the percentage of TSP served and the orange area denotes the percentage of TSP not served. 


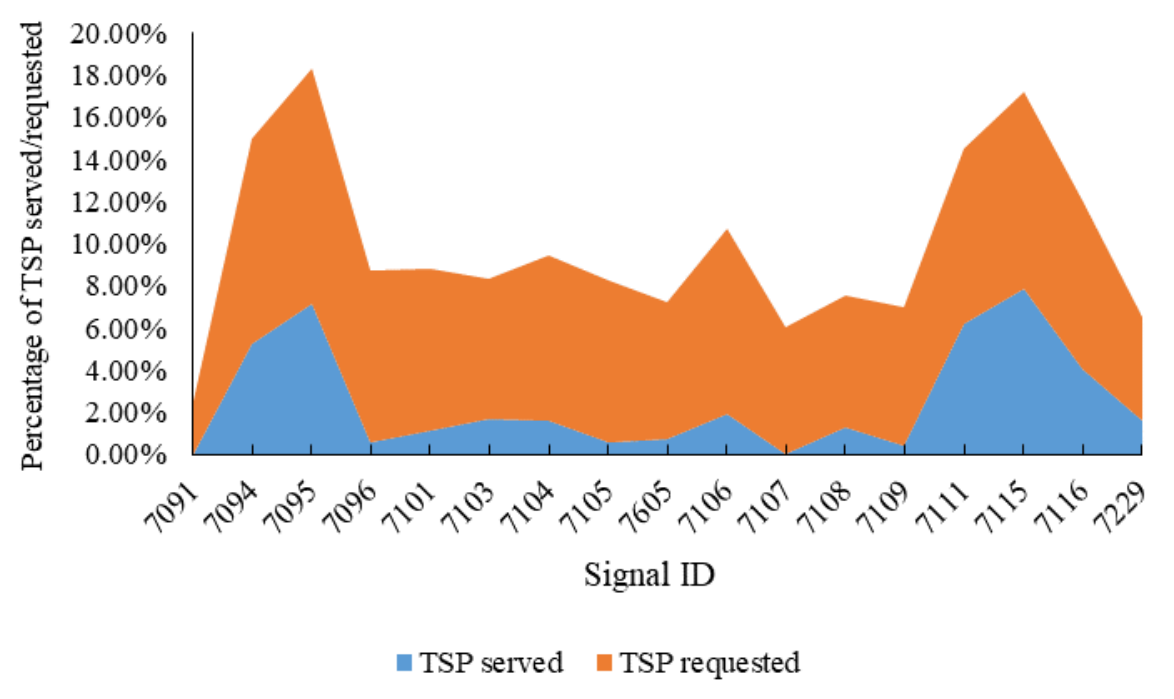

(a) Rate of TSP requested and served before signal retiming

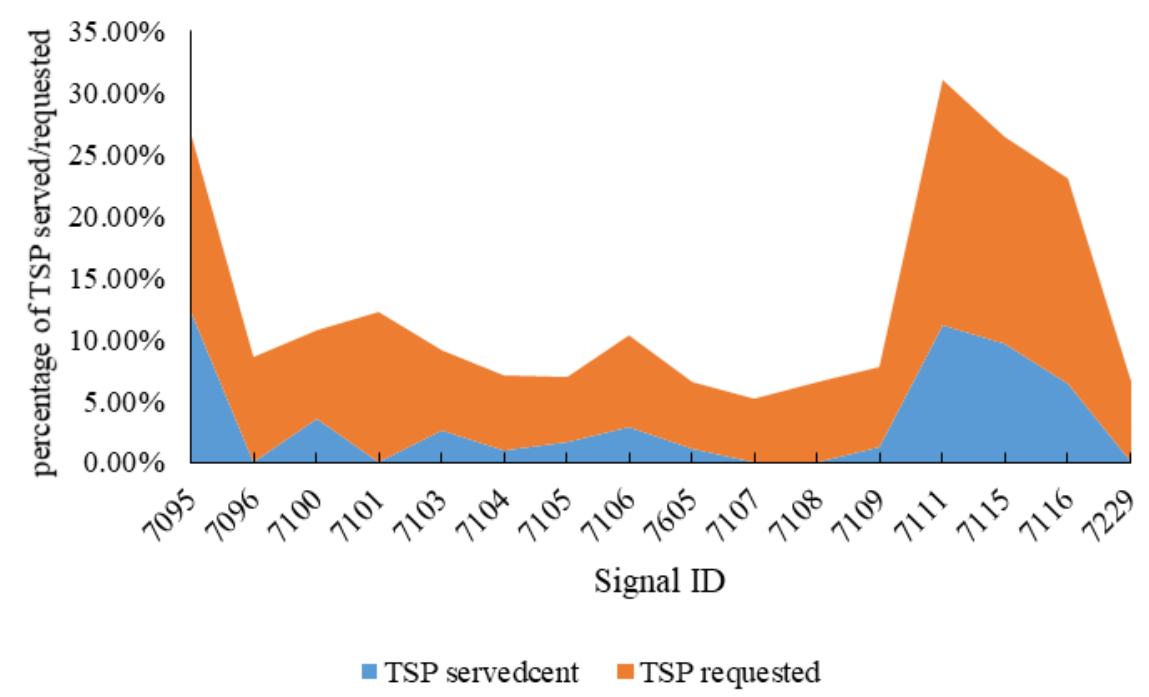

(b) Rate of TSP requested, and TSP served after signal retiming

Figure 3.3: Rate of TSP requested and TSP served for various signal plans

It can be observed that the majority of requested TSP was not served under the two signal timing plans. One major reason is that although most buses request TSP, they can pass through the intersection during the green interval, causing the requested TSP to be canceled. The figure shows that the TSP service rate is super low at some intersections. This is due to the fact that the volume of the side streets is so low that more green times are allocated to the main street. In general, the average rate of TSP served before signal retiming is $33.13 \%$, which is lower than that of $35.29 \%$ after signal retiming. 


\subsubsection{Reliability Analysis}

One critical reason to deploy this $\mathrm{CV}$ corridor is to improve the bus reliability by granting TSP. The strategy to measure bus reliability is based on the UTA standard in this study. In detail, all on-time arrivals for each time point are counted and then they are divided by the total arrivals at that time point. The evaluation of reliability is assisted by the UTA reliability dataset. Figure 3.4 shows the reliability before and after signal retiming for both the northbound and southbound directions. It is observed that the average reliability for northbound and southbound before signal retiming is $89.44 \%$ and $92.09 \%$. After signal retiming, they have improved to $92.07 \%$ and $93.28 \%$. The main reason is the TSP-served ratio improves after signal retiming, which leads more late status to transfer to on-time status.

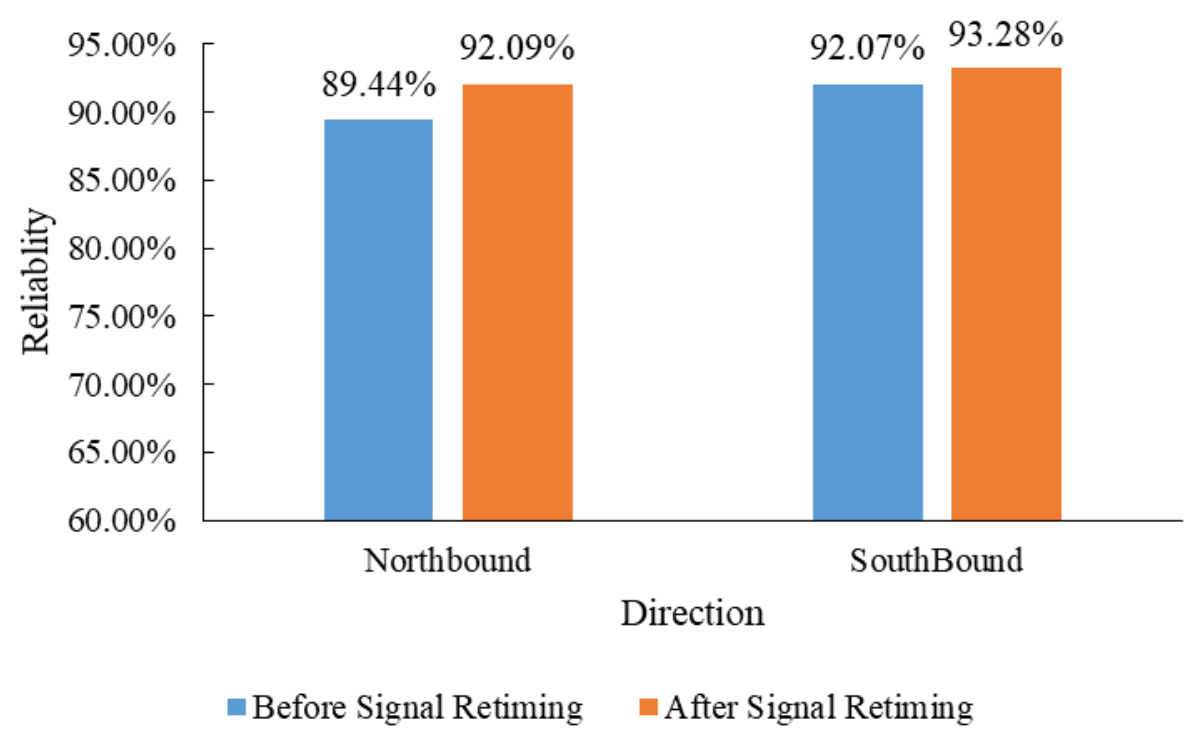

Figure 3.4: Reliability for northbound and southbound of route 217 before and after signal retiming

\subsubsection{Travel/Running Time and Speed Analysis}

Bus travel time and bus running time are two other important measurements to assess the impact of signal retiming. Bus travel time means the time a bus travels from the departure station to the terminal station. Bus running time can be obtained by deducting dwell time from travel time. Figure 3.5 shows the travel time of the two signal timing plans for both the northbound and southbound directions. It can be observed that northbound and southbound travel times after signal retiming are 3625.06 seconds and 4095.07 seconds, which are lower than the corresponding time before signal retiming. This indicates that the speed management of signal retiming results in an improvement in bus travel time. This improvement is mainly caused by the decrease in the running time, as shown in Figure 3.6. Another aspect is due to the higher served TSP ratio after signal retiming. More specifically, the signal granted more TSP requests during the red 
interval after signal retiming, resulting in less stopping time at intersections. Based on the running time and the length of this corridor, the average speed before and after signal retiming can be calculated. The average speed for northbound and southbound after signal retiming are $23.20 \mathrm{~km} / \mathrm{h}$ and $20.81 \mathrm{~km} / \mathrm{h}$, which are higher than that of 19.67 $\mathrm{km} / \mathrm{h}$ and $19.72 \mathrm{~km} / \mathrm{h}$ before signal retiming. Note that the calculated speed may be lower than the actual traveling speed of buses on the road since the time in and out of the bus station is considered.

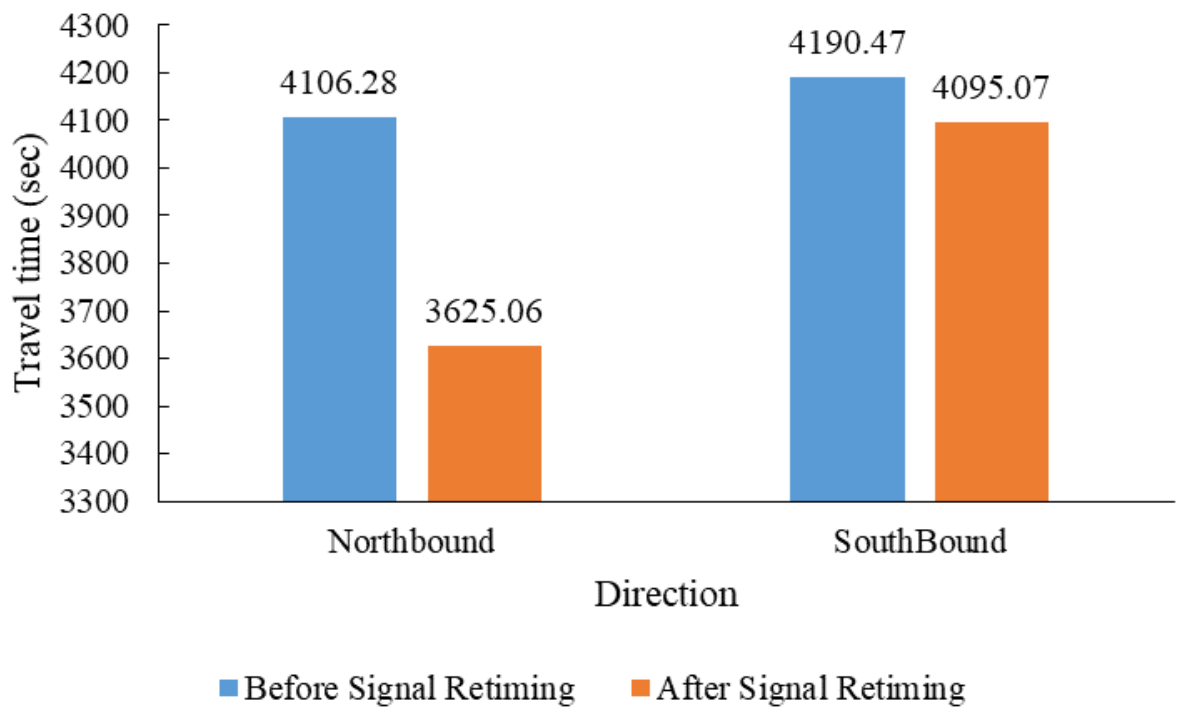

Figure 3.5: Bus travel time for northbound and southbound of route 217 before and after signal retiming

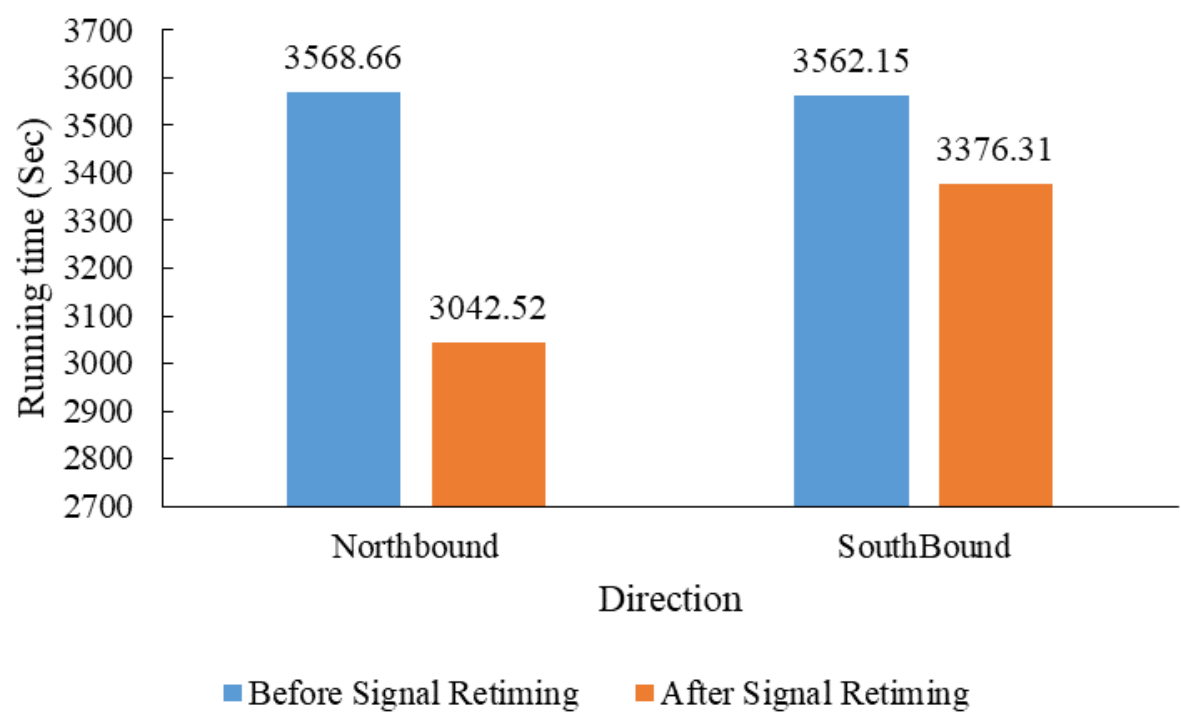

Figure 3.6: Bus running time for northbound and southbound of route 217 before and after signal retiming 


\subsection{CONCLUSION}

TSP has great potential to reduce bus delays at intersections, improve transit operational reliability, and consequently increase transit ridership with improved service. To improve the effectiveness of TSP, UDOT applied the speed management strategy of signal coordination and signal retiming. With the emerging CV technology, highresolution data can be easily acquired and applied to assess the impact of the speed management strategy on TSP. In this study, a CV corridor located in Salt Lake City, UT, was selected to conduct such an evaluation. Traffic signals along this corridor are controlled with a specific coordination plan and this plan underwent retiming in October 2018. Assisted by three different datasets, DSRC dataset, ATSPM dataset, and UTA dataset, this study analyzed the TSP performance in terms of TSP-served ratio, bus reliability, bus travel time, and bus running time before and after signal retiming.

Results indicated that the ratio of TSP served is $33.12 \%$ before signal retiming, which is lower than that of $35.29 \%$ after signal retiming. As a result, the bus reliability for the northbound and southbound of the corridor improved by $2.65 \%$ and $1.21 \%$, respectively, after signal retiming. In addition, bus travel time and bus running time are reduced after signal retiming, which results in an improved bus speed after signal timing. All those measurements indicate that the speed management strategy implemented along this CV corridor results in an improvement of TSP. 


\subsection{USING HIGH-RESOLUTION TRAFFIC DATA FOR EVALUATING MULTIMODAL MOBILITY}

This chapter discusses the feasibility of using controller event-based traffic data for estimating multimodal signal performance measures. This chapter is prepared based on a published journal article (Karimpour et al., 2021).

\subsection{BACKGROUND}

In this chapter, the feasibility of using high-resolution traffic data for evaluating multimodal signal performance measures is discussed. Signal performance measures (SPM) provide valuable information to the agencies to take proactive steps toward the safety, operation, and management of every individual intersection. Signal performance measures can be divided into three categories: 1) capacity measures, such as cycle length, green duration, and traffic volume; 2) progression measures, such as arrival on red, arrival on green, and platoon profile; and 3) multimodal measures, such as pedestrian demand, pedestrian delay, and preemption (Day et al., 2014; Day et al., 2008). While SPM are a great tool for system operations, they have been primarily focused on vehicular-centric measures. Performance measures focused on multimodal users are a pressing need for future research (Huang et al., 2018). Currently, pedestrian actuation and delay are the only available performance measures pertinent for multimodal SPM in the ATSPM framework. Pedestrian actuation is defined as the push-button activation, while delay represents the difference between the time when the push-button was first pressed and the start of the WALK indication. Delay, in general, is one of the most significant SPM that quantify the operation level of service of intersections and is the most frequent measure used for intersection mobility. For the last decade, many studies have focused on various analytical and artificial intelligence approaches for estimating vehicle delays (Qiao et al., 2002; Wei et al., 2015). However, less effort has been expended on methods to estimate pedestrian delay.

In this chapter, a pedestrian estimation method with higher accuracy over the conventional deterministic methods, such as $\mathrm{HCM}$, is proposed. The proposed method uses high-resolution event-based data to indirectly estimate pedestrian delay. Previous studies showed that pedestrian delay distribution highly depends on pedestrian arrival rate (Fi \& Igazvölgyi, 2014). Further, it has been widely shown that the pedestrian arrival rate is non-uniformly distributed (Li et al., 2005; Zheng \& Elefteriadou, 2017). Therefore, this study proposed a method to estimate pedestrian delay based on a mixture distribution. A mixture or finite mixture distribution is the probability distribution of a random response variable that can be characterized as a function of other random variables (Lao et al., 2012). Due to the adaptability and applicability of mixture models, 
they have been widely applied across different fields within traffic and transportation engineering, such as vehicle classification and speed estimation (Lao et al., 2012); truck weight distribution estimation (Hernandez, 2017; Hernandez \& Hyun, 2020; Regehr et al., 2020); arterial travel time estimation (Q. Yang et al., 2018); and freeway travel time reliability (S. Yang \& Cooke, 2018).

\subsection{LITERATURE REVIEW}

Pedestrian delay is an important performance measure that is used to describe pedestrian travel and to evaluate the level of service for pedestrians at intersections (HCM, 2010). Previous research shows that pedestrians become impatient when they experience delays greater than 30 seconds per pedestrian (Dunn \& Pretty, 1984). Alternately, they are likely to show high degrees of compliance when delays are less than 10 seconds per pedestrian. Some studies have developed analytical approaches to estimate pedestrian delay. The commonly used model in the HCM 2010 and HCM $6^{\text {th }}$ edition to estimate pedestrian delay was formulated as a function of cycle length and effective walk time (Elefteriadou, 2016). This model was developed by Pretty (1979) assuming uniform arrival rates and fixed pedestrian timing. Braun and Roddin (1978) suggested a modification to include a fraction of pedestrians who comply with the signal indication. The modified equation assumes that noncomplying pedestrians incur no delay. Virkler suggested a modification to the equation proposed by Pretty (5). His observations showed that $69 \%$ of the clearance period was used by pedestrians as effective green.

Many researchers would still argue regarding the accuracy of the estimated pedestrian delay using the HCM method (Chilukuri \& Virkler, 2005; Hubbard et al., 2008; Kothuri et al., 2012). For instance, Chilukuri and Virkler conducted field studies of pedestrian delay and showed that pedestrian arrivals at signalized intersections in a coordinated system were not random and the observed pedestrian delays were significantly different than the pedestrian delay estimated using the HCM method (Chilukuri \& Virkler, 2005). To tackle this problem, recent technological advances in smart sensors have allowed cities to collect a large amount of multimodal data to estimate pedestrian delay. Automated Traffic Signal Performance Measures (ATSPMs) is one of the most recent technological advancements that utilize high-resolution event-based data, signal phasing, and overlap states and data analysis techniques to generate metrics that can be used to provide insights into multimodal system operation (Day, Taylor, et al., 2016). The performance metrics obtained using ATSPM could be used to monitor and evaluate the operation of multimodal transportation, such as pedestrian delay. While signal performance measures are a great tool for system operations, they have been primarily focused on vehicular measures. SPM focused on multimodal users is a pressing need for future research (Huang et al., 2018). However, transportation agencies are still facing challenges on how to incorporate the high-resolution event-based data for obtaining multimodal signal performance measures, such as pedestrian delay. 


\subsection{STUDY SITES AND DATA COLLECTION}

Ina Rd. corridor in Pima County, AZ, was selected as the study corridor. This is a westeast corridor connecting the east side of Tucson to Interstate 10, with a speed limit of 45 $\mathrm{mi} / \mathrm{hr}$. This corridor is a multimodal arterial with high volumes of passenger cars, transit, and pedestrian activity. Four major signalized intersections on this corridor, as illustrated in Figure 4.1-a, were selected as study locations. All the intersections have four legs, with two through movement lanes for the major streets and dedicated left-turn lane(s) that separate left-turning vehicles from through movements. A ring barrier diagram for the signal timing plan deployed on these intersections is illustrated in Figure 4.1-b. Pima County Department of Transportation (PCDOT) oversees the operation of this corridor. The selected intersections follow actuated-coordinated timing, with the major approaches in coordination (Phases $2 \& 6$ ) while the minor approaches are uncoordinated (Phases 4 \& 8).

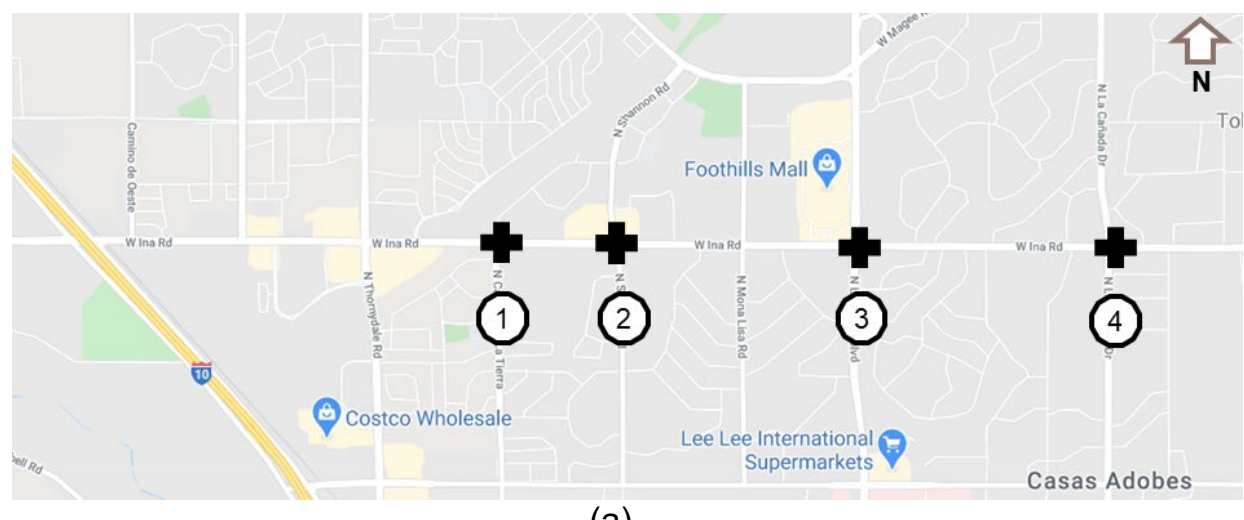

(a)

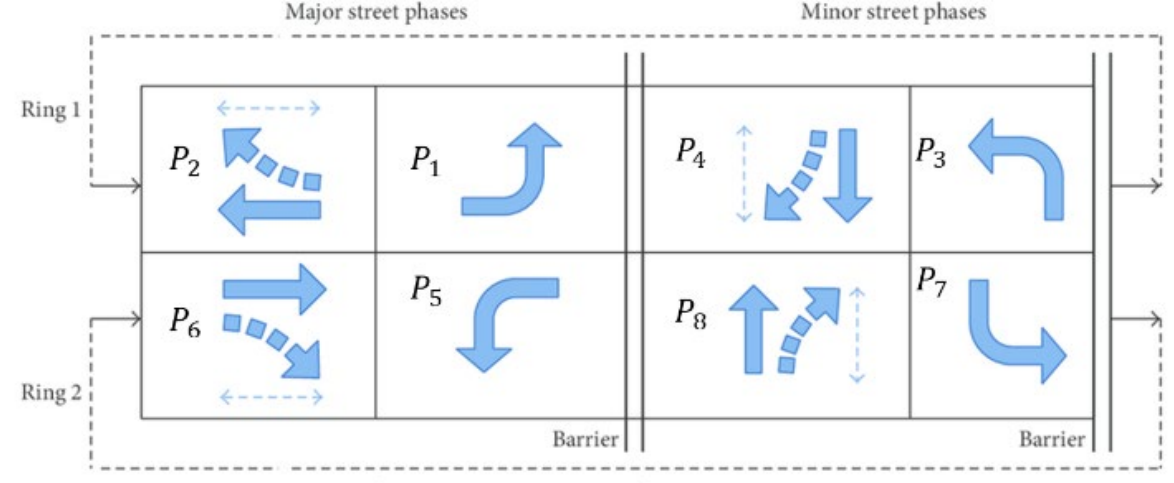

(b)

Figure 4.1: a) Ina Rd. Corridor; b) Sample ring barrier diagram

These intersections were specifically chosen as study locations as they are all equipped with Miovision smart sensors. These sensors provide high-resolution event-based data for multimodal transportation. Raw data from these sensors are accessible through an application programming interface (API) provided by the Miovision team. The raw data includes cycle length, vehicle and pedestrian delay, and pedestrian effective green 
duration. For this study, data from January and February 2020 were obtained from the Miovison API for the four selected intersections.

\subsection{METHODOLOGY}

As shown in the literature, there have been limited studies with a focus on estimating pedestrian delay. Using the high-resolution data collected from the smart sensors located at the considered intersections, the current study proposes finite mixture modeling as a viable method for estimating pedestrian delay. Specifically, the present work utilizes a Gaussian mixture model (GMM). The application of a GMM is used to characterize pedestrian delay distributions as a function of specific covariates (e.g., traffic flow, cycle length, pedestrian effective green duration, etc.). A GMM is a weighted sum, or superposition, of $K$ component Gaussian densities (also called a mixture of Gaussians):

$$
p(x)=\sum_{k=1}^{K} \pi_{k} \mathcal{N}\left(x \mid \mu_{k}, \Sigma_{k}\right)
$$

where $x$ is a $D$-dimensional continuous measurement of pedestrian delay, $\pi_{k}$ represents the mixture weights, and $\mathcal{N}\left(x \mid \mu_{k}, \Sigma_{k}\right)$ represents the component Gaussian densities. The component Gaussian density is a $D$-variate Gaussian function such that:

$$
\mathcal{N}\left(x \mid \mu_{k}, \Sigma_{k}\right)=\frac{1}{(2 \pi)^{\frac{D}{2}}\left|\Sigma_{k}\right|^{\frac{1}{2}}} e^{\left[-\frac{1}{2}\left(x-\mu_{k}\right)^{\prime} \Sigma_{k}^{-1}\left(x-\mu_{k}\right)\right]}
$$

where $\mu_{k}$ is a component-specific mean vector, $\Sigma_{k}$ is a component-specific covariance matrix, and $\pi_{k}$ must satisfy:

$$
\sum_{k=1}^{K} \pi_{k}=1
$$

For the mixing weights to satisfy the conditions of being probabilities, $p(x) \geq 0$ and $\mathcal{N}\left(x \mid \mu_{k}, \Sigma_{k}\right) \geq 0$ implies that $\pi_{k} \geq 0 \forall k$. Therefore, values for $\pi_{k}$ are constrained to be between zero and one. Based on the presented formulae, the form of the Gaussian mixture is controlled by $\mu_{k}, \pi_{k}$, and $\Sigma_{k}$, where they are estimated via maximum likelihood:

$$
L L\left(\pi_{k}, \mu_{k}, \Sigma_{k}\right)=\sum_{n=1}^{N} \ln \left[\sum_{k=1}^{K} \pi_{k} \mathcal{N}\left(x \mid \mu_{k}, \Sigma_{k}\right)\right]
$$

For this study, cycle length, effective pedestrian effective green duration, and traffic flow (VPH) were used as the covariates to estimate the component-specific mean and component-specific covariance matrix of the pedestrian delay. Assuming pedestrian delay has a Gaussian distribution, such that:

$$
x \sim \mathcal{N}_{k}\left(\bar{\mu}_{k}, \Sigma_{k}\right)
$$


the component-specific mean $\left(\bar{\mu}_{k}\right)$ and the component-specific covariance matrix $\left(\Sigma_{k}\right)$ are a function of the specific covariates as below:

$$
\begin{gathered}
\bar{\mu}_{k}=\beta_{0, k}+\beta_{j, k} X+\varepsilon \\
\Sigma_{k}=\Sigma_{k}(X)
\end{gathered}
$$

where $X$ is a vector of the covariates. $\beta_{i, k}$ are the estimated coefficients of the covariates for the $k^{\text {th }}$ Gaussian mixture component using maximum likelihood. The results from the mixture modeling are described in the next section.

\subsection{RESULTS}

\subsubsection{Correlation Analysis}

Identifying the specific covariates that can explain the pedestrian delay distribution function is beneficial when the measured pedestrian delay information is not available. In this study, three covariates, cycle length, pedestrian effective green duration, and VPH were used as potential candidates to model pedestrian delay. To avoid multicollinearity issues during the modeling process, the correlation between these covariates was calculated using Pearson and Spearman correlation tests (Pearson, 1895) (Wissler, 1905). Figure 4.2 depicts the correlation among these covariates.

\section{Pearson Correlation}

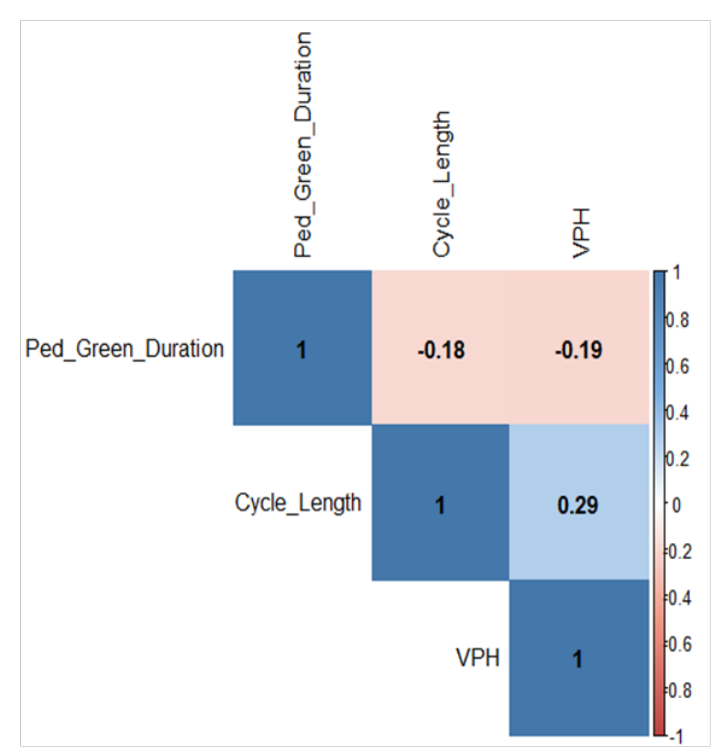

Spearman Correlation

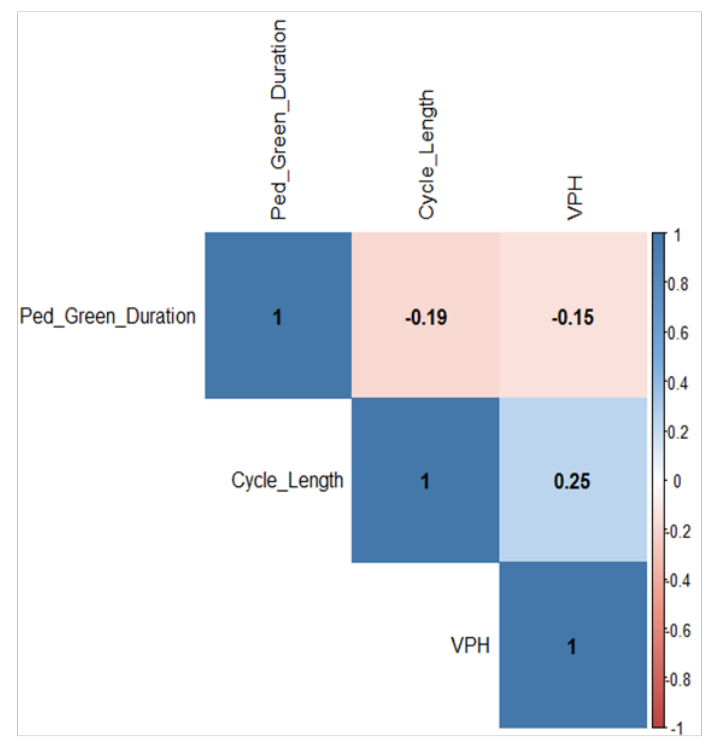

Figure 4.2: Correlation analysis among the covariates

The results indicate that there exists a negative correlation between VPH and the pedestrian effective green duration (Ped-Green-Duration), cycle length (Cycle-Length), and pedestrian effective green duration, and a positive correlation between cycle length 
and traffic flow. However, for all three cases, the magnitude of the correlation is lower than 0.30 and, therefore, no strong correlation could be observed.

\subsubsection{Model Development Analysis}

Next, seven models with various combinations of the covariates with two, three, and four mixture components were calibrated for each intersection. To identify the most appropriate combination of covariates and the best number of mixture components, the Akaike information criterion (AIC), Bayesian information criterion (BIC), and loglikelihood values were estimated for the individual models. The AIC value denotes the relative distance between the true and the estimated likelihood function of the observed data (Hirotugu, 1974), the BIC value denotes an estimate of a function of the posterior model being accurate (Stone, 1979), and the log-likelihood measures the goodness of fit of a statistical model. Therefore, a lower AIC and BIC mean a model closer to the real data and a higher log-likelihood (i.e., a value closer to zero) shows a model with a better fit. Being that maximum likelihood estimation was used to estimate the Gaussian mixture component parameters $\left(\mu_{k}, \pi_{k}\right.$, and $\left.\Sigma_{k}\right)$, the log-likelihood criterion was selected as the measure for identifying the most appropriate model. Therefore, the models with the highest log-likelihood values (closest to zero) were selected as the final model representing pedestrian delay at each intersection. The summary of the selected models with their corresponding $\mathrm{AIC}, \mathrm{BIC}$, and log-likelihood are demonstrated in Table 4.1.

Based on the log-likelihood values for W Ina Rd. and N Shannon Rd., W Ina Rd. and N La Cholla Blvd., and W Ina Rd. and N La Cañada Dr., a four-component mixture model with cycle length and VPH as the covariates was the best model that represents pedestrian delay distribution. For W Ina Rd. and N Camino De La Tierra a fourcomponent mixture model with cycle length and pedestrian green duration as the covariates was the best model.

The reason behind the difference in the covariates that represent the pedestrian delay function for W Ina Rd. and N Camino De La Tierra compared to other intersections could be the traffic patterns on this intersection. Relatively, this intersection is experiencing a much lower traffic volume on its minor streets (high volume of 84 vehicles per hour) compared to the other intersections. Therefore, VPH might not be the best covariate representing pedestrian delay function at this intersection.

After identifying the final covariates and number of components for the mixture model of each intersection, the estimated coefficients of the covariates for each Gaussian mixture component $\left(\beta_{i, k}\right)$, the component-specific covariance $\left(\Sigma_{k}\right)$ and the prior probability of their component $\left(\pi_{k}\right)$ are tabulated in Table 4.1. The $\beta_{i, k}$ from this table were inserted into Equation 6 to identify the center of each mixture component, the componentspecific covariance was used to define the width of each component, and the prior probability $\left(\pi_{k}\right)$ was used to define how big or small the Gaussian function will be. 
Table 4.1 Detailed Information on the Selected Models

\begin{tabular}{|c|c|c|c|c|c|}
\hline \multirow[t]{2}{*}{ Intersection } & \multirow[t]{2}{*}{ Variable } & \multicolumn{4}{|c|}{ Estimated Coefficient } \\
\hline & & $\mathrm{GMM}^{* *} \# 1$ & GMM \#2 & GMM \#3 & GMM \#4 \\
\hline \multirow{7}{*}{$\begin{array}{c}\text { W Ina Rd. \& } \\
\text { N Camino } \\
\text { De La } \\
\text { Tierra }\end{array}$} & Intercept & $1,544.84$ & -38.17 & -299.74 & $-1,907.37$ \\
\hline & Cycle Length & 0.50 & 0.02 & 0.13 & 1.47 \\
\hline & $\mathrm{VPH}^{*}$ & - & - & - & - \\
\hline & $\begin{array}{l}\text { Effective Pedestrian Green } \\
\text { Duration }\end{array}$ & -305.62 & 8.98 & 62.63 & 365.25 \\
\hline & Variance $\left(\Sigma_{k}\right)$ & 30.99 & 5.17 & 14.56 & 5.48 \\
\hline & Prior Probability $\left(\pi_{k}\right)$ & 0.41 & 0.32 & 0.20 & 0.06 \\
\hline & $A I C=9,301.35$ & $B I C=9,393.92$ & \multicolumn{3}{|c|}{ log-likelihood = -4,639.94 } \\
\hline \multirow{7}{*}{$\begin{array}{c}\text { W Ina Rd. \& } \\
\text { N Shannon } \\
\text { Rd. }\end{array}$} & Intercept & 10.46 & 10.12 & 6.83 & 11.63 \\
\hline & Cycle Length & 0.11 & 0.74 & 0.02 & 0.31 \\
\hline & VPH & 0.01 & 0.01 & 0.00 & 0.03 \\
\hline & $\begin{array}{l}\text { Effective Pedestrian Green } \\
\text { Duration }\end{array}$ & - & - & - & - \\
\hline & Variance $\left(\Sigma_{k}\right)$ & 10 & 22.93 & 5.37 & 19.51 \\
\hline & Prior Probability $\left(\pi_{k}\right)$ & 0.28 & 0.23 & 0.17 & 0.32 \\
\hline & $\mathrm{AIC}=17,536.46$ & $\mathrm{BIC}=17,640.81$ & \multicolumn{3}{|c|}{ log-likelihood $=-8,749.23$} \\
\hline \multirow{7}{*}{$\begin{array}{c}\text { W Ina Rd. \& } \\
\text { N La Cholla } \\
\text { Blvd. }\end{array}$} & Intercept & 0.39 & -4.16 & -1.22 & 8.06 \\
\hline & Cycle Length & 0.23 & 0.58 & 0.42 & 0.84 \\
\hline & VPH & -0.01 & 0.03 & 0.00 & 0.00 \\
\hline & $\begin{array}{l}\text { Effective Pedestrian Green } \\
\text { Duration }\end{array}$ & - & - & - & - \\
\hline & Variance $\left(\Sigma_{k}\right)$ & 13.98 & 11.35 & 19.9 & 16.1 \\
\hline & Prior Probability $\left(\pi_{k}\right)$ & 0.40 & 0.14 & 0.31 & 0.15 \\
\hline & $\mathrm{AIC}=12,276.85$ & $\mathrm{BIC}=12,374.05$ & \multicolumn{3}{|c|}{ log-likelihood $=-6,119.43$} \\
\hline \multirow{7}{*}{$\begin{array}{c}\text { W Ina Rd. \& } \\
\text { N La } \\
\text { Cañada Dr. }\end{array}$} & Intercept & -5.57 & 42.68 & -29.69 & -1.08 \\
\hline & Cycle Length & 1.02 & -0.30 & 0.52 & 0.66 \\
\hline & VPH & -0.01 & 0.02 & 0.00 & 0.00 \\
\hline & $\begin{array}{l}\text { Effective Pedestrian Green } \\
\text { Duration }\end{array}$ & - & - & - & - \\
\hline & Variance $\left(\Sigma_{k}\right)$ & 10.65 & 4.93 & 14.07 & 16.33 \\
\hline & Prior Probability $\left(\pi_{k}\right)$ & 0.16 & \multirow{2}{*}{\multicolumn{3}{|c|}{\begin{tabular}{c|c|}
0.06 & 0.48 \\
log-likelihood $=-1,147.44$
\end{tabular}}} \\
\hline & $\mathrm{AIC}=2,332.87$ & & & & \\
\hline
\end{tabular}

${ }^{* *} \mathrm{GMM}=$ Guassian Mixture Model; *VPH= Traffic flow (veh. $/ \mathrm{Hr}$.)

To provide a side-by-side accuracy evaluation, the empirical histograms of the actual pedestrian delay were plotted against the PDFs of the pedestrian delay developed by the mixture models, as shown in Figure 4.3. The blue line shows the PDF of the estimated delay using the mixture models and the gray boxes are the empirical histograms of the pedestrian delay. 


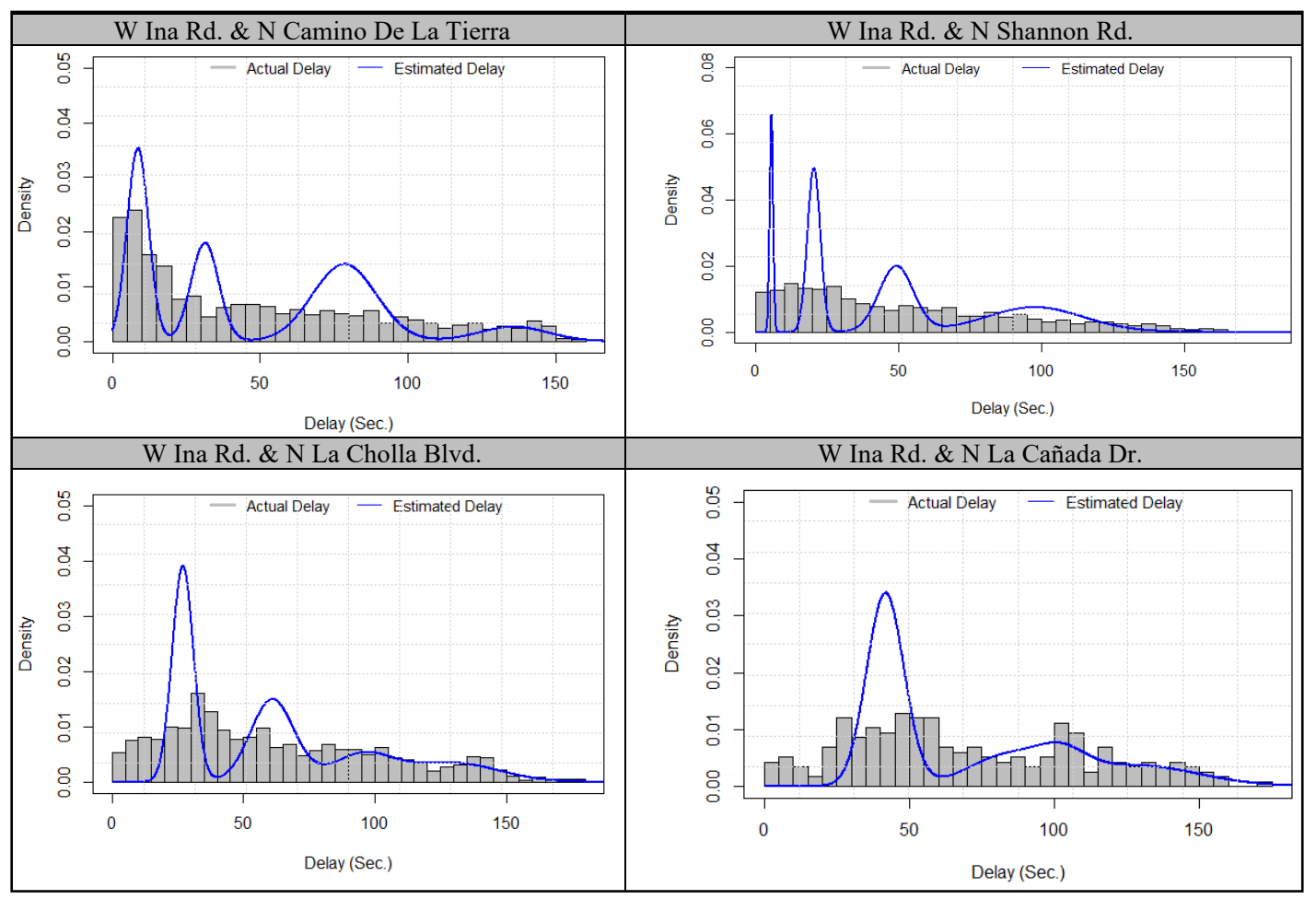

Figure 4.3: Probability distribution function of pedestrian delay

The density plots in Figure 4.3 show that the estimated PDF using four mixture components are able to capture and track the trend of the empirical histogram. The mixture models were more robust while estimating higher pedestrian delay. That is, the estimated PDF was much closer to the empirical histogram of the data.

\subsubsection{Model Evaluation}

In order to compare the accuracy of the proposed method with existing literature, three conventional pedestrian delay estimation methods were selected.

1- HCM 2010 Method (similar to HCM $6^{\text {th }}$ edition) (Elefteriadou, 2016; Xuan Wang \& Tian, 2010):

$$
d_{p}=\frac{0.5(C-g)^{2}}{C}
$$

2- Virkler Method (Virkler, 1998):

$$
d_{p}=\frac{(c-(g+0.69 A))^{2}}{2 c}
$$

3- Dunn Method (Dunn \& Pretty, 1984): 


$$
d_{p}=\frac{(g+10)^{2}}{2(g+15)}
$$

where $d_{p}$ denotes the average delay per pedestrian (s), $C$ denotes the cycle length (s), $g$ is the pedestrian effective walk time (s), and $A$ is the clearance time (s). Figure 4.4 compares the average pedestrian delay at the study intersections with the estimated values from four different models.

The following findings were observed from this figure.

1. Based on Equation (4-10), in the Dunn method pedestrian effective green duration $(g)$ is the only covariate used for estimating the pedestrian delay function. The average amount of effective pedestrian green duration for all the intersections is 5.68 seconds, with a variance of 0.94 seconds. Therefore, one would expect to see a constant flat curve when estimating pedestrian delay.

2. The Virkler method is able to capture most of the fluctuation of pedestrian delay throughout the day, but it heavily overestimates the actual delay. Comparing with the proposed method, this method uses cycle length, effective green duration, and clearance time for pedestrians. The Virkler method is overestimating the pedestrian delay, on average, by $28.06,22.27,32.05$, and 14.26 seconds on $\mathrm{W}$ Ina Rd. \& N Camino De La Tierra, W Ina Rd. \& N Shannon Rd., W Ina Rd. \& N La Cholla Blvd., and W Ina Rd. \& N La Cañada Dr, respectively.

3. Compared with Dunn and Virkler, HCM is the most accurate method. The HCM method is also able to capture all the fluctuation of pedestrian delay throughout the day. HCM method only uses cycle length as a covariate defining the pedestrian delay function. However, since the HCM method does not integrate the impact of traffic patterns during the day, it sometimes heavily overestimates or underestimates the actual value. For instance, $\mathrm{HCM}$ overestimates pedestrian delay throughout the day for W Ina Rd. \& N Camino De La Tierra and W Ina Rd. \& N La Cholla Blvd, on average, by 4.74 and 4.08 seconds, respectively. For W Ina Rd. \& N Shannon Rd. it overestimates pedestrian delay on peak hours, on average, by 3.82 seconds and underestimates during off-peak, on average, by 2.43 seconds. For W Ina Rd. \& N La Cañada Dr. it underestimates pedestrian delay on peak hours, on average, by 12.07 seconds and overestimates during off-peak, on average, by 2.97 seconds.

4. The proposed method is able to capture and track all the fluctuation of pedestrian delay during the day. In addition, based on the results from Figure 4.4, the proposed model is robust toward the spikes happening during the day. This is because the proposed method uses both information from cycle length and traffic flow as covariates representing pedestrian delay function (for one intersection cycle length and effective pedestrian delay duration). 


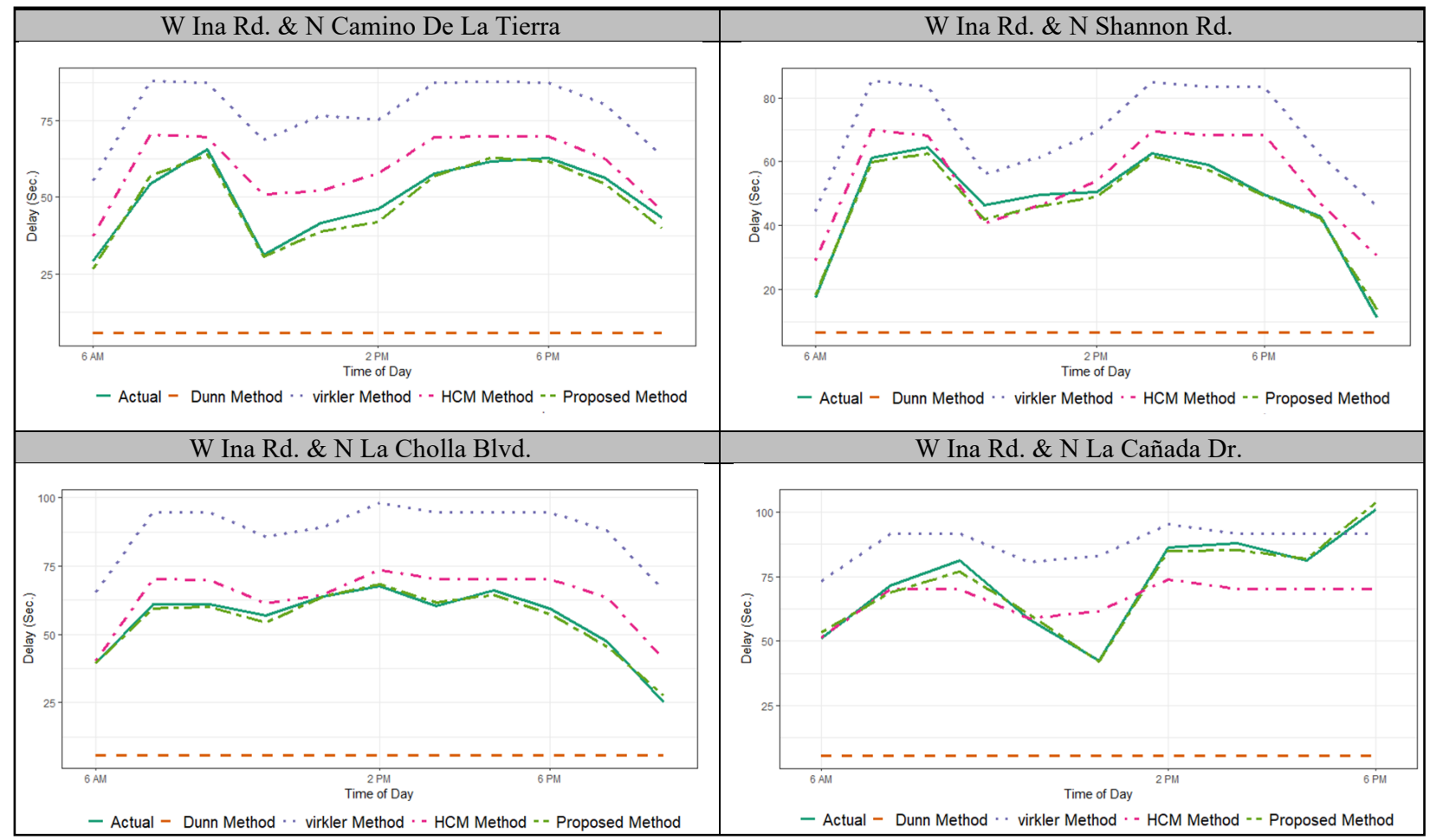

Figure 4.4: Model evaluation-average delay

To quantitatively compare the accuracy of each model, root mean square error (RMSE) and mean absolute error (MAE) were selected as measures of effectiveness (MOEs). RMSE is related to the standard deviation of the estimated error and measures the weighted average of estimation error, and MAE is related to the absolute value of the estimation error. RMSE and MAE can be calculated based on the following equations:

$$
\begin{aligned}
R M S E & =\sqrt{\frac{1}{n} \sum_{i=1}^{n}\left(\widehat{Y}_{t}-Y_{t}\right)^{2}} \\
M A E & =\frac{\sum_{i=1}^{n}\left|\widehat{Y}_{t}-Y_{t}\right|}{n}
\end{aligned}
$$

where $n$ denotes the sample size, and $\hat{Y}_{t}$ and $Y_{t}$ are the estimated and observed data, respectively.

Table 4.2 quantifies the results of the model comparison. The overall results of the MOEs clearly showed that the proposed method outperforms all the conventional methods irrespective of the intersection. The values in this table are based on the average delay over the data collection period. 
Table 4.2 Comparison Results (Average Delay)

\begin{tabular}{|c|c|c|c|c|c|}
\hline \multirow{2}{*}{ Methods } & MOEs & $\begin{array}{c}\text { W Ina Rd. \& N } \\
\text { Camino De La } \\
\text { Tierra }\end{array}$ & $\begin{array}{c}\text { W Ina Rd. \& N } \\
\text { Shannon Rd. }\end{array}$ & $\begin{array}{c}\text { W Ina Rd. \& N } \\
\text { La Cholla } \\
\text { Blvd. }\end{array}$ & $\begin{array}{c}\text { W Ina Rd. \& N } \\
\text { La Cañada Dr. }\end{array}$ \\
\hline $\begin{array}{c}\text { Proposed } \\
\text { Method }\end{array}$ & RMSE (Sec.) & 14.69 & 12.32 & 11.63 & 15.69 \\
\cline { 2 - 6 } & MAE (Sec.) & 11.13 & 9.19 & 9.52 & 11.26 \\
\hline \multirow{2}{*}{ HCM 2010 } & RMSE (Sec.) & 38.98 & 40.24 & 39.46 & 42.92 \\
\cline { 2 - 6 } $\begin{array}{c}\text { Virkler } \\
\text { Method }\end{array}$ & RME (Sec.) & 32.75 & 34.25 & 33.47 & 37.31 \\
\cline { 2 - 6 } $\begin{array}{c}\text { Dunn } \\
\text { Method }\end{array}$ & MAE (Sec.) & 52.77 & 44.15 & 49.62 & 41.95 \\
\cline { 2 - 6 } & MAE (Sec.) & 61.02 & 38.36 & 42.91 & 36.49 \\
\hline
\end{tabular}

The low RMSE of the proposed method compared to other methods shows the absence of large errors in the proposed method. MAE does not consider the direction of error, and all errors have equal weights. Comparing the amount of MAE among the methods, the proposed method also estimates pedestrian delay with better accuracy.

Calibrating estimation models is usually a costly, complex, and time-consuming procedure. In addition, it is not always feasible for agencies to collect sufficient traffic data at each intersection on a network to perform variable selection and calibration. Therefore, it is important to calibrate a few models that can be transferred to other intersections. The succeeding section will discuss, in-depth, the transferability of the proposed model.

\subsection{CONCLUSION}

In this study, a novel method based on finite mixture modeling was proposed to estimate pedestrian delay. Initially, the proposed method identifies the covariates that best explain the pedestrian delay. Then, a Gaussian mixture model (GMM) was used to characterize pedestrian delay distributions as a function of these specific covariates.

Four intersections on Ina Rd. were selected as the study locations and individual models were calibrated for each intersection. Cycle length and traffic flow were the most appropriate covariates that could explain the pedestrian delay function for three out of four intersections, and cycle length and effective pedestrian green duration were the most appropriate covariates that could explain the pedestrian delay function for the other intersection. The results of estimating the pedestrian delay using the calibrated model at each intersection showed the proposed method was able to capture and track the actual delay fluctuation during the day with an average of $10 \%$ of mean absolute error. Further, the result of the test of disaggregated prediction showed that the proposed method was transferable to other intersections with similar specifications.

The application of the proposed method could be beneficial to the transportation agencies in three capacities: 1) providing a more reliable, robust, and accurate approach for estimating pedestrian delay at signalized intersections where sensors are not available 
to collect pedestrian delay; 2) a tool to develop pedestrian delay PDF for analyzing the risk of pedestrians violating the signal; and 3) calibrating a network-wide model for estimating pedestrian delay at all intersections without the need to use additional resources. 


\subsection{CONCLUSION AND RECOMMENDATION}

This chapter describes the study summary, conclusion, and future directions regarding speed management strategies and their impact on arterial mobility and safety.

\subsection{CONCLUSION}

Improved multimodal speed management strategy will foster a safer community that will, in turn, encourage the use of eco-friendly mode choices on the corridors and encourage more people to walk and bike. This study addressed data-driven multimodal speed management strategies for traditional corridors using traffic sensors, and for future evaluation of connected vehicle-based strategies. The outcome of the three main objectives of this study were as below:

- Evaluate the impact of speed management strategies along conventional arterials using smart sensor data.

To evaluate the potential impact of speed management strategies on arterial mobility and safety, an observational before-after study was conducted on an arterial road in Tucson, AZ. The impact of speed feedback signs (SFS) on arterial mobility was evaluated at intersection and link levels. Then, the effect of SFS on the dispersion of operating speed was investigated by developing a speed change behavior model. Finally, the safety benefit of an active SFS was quantified at the link-speed level using the proposed driver speed change model. The results showed statistically significant speed reduction was found at three out of four links after enabling the SFS. In addition, it was found that the impact of SFS on drivers' behavior is a function of their approaching speed. The results of the safety assessment of SFS showed that at an arterial with a link speed of $35 \mathrm{mph}$, the benefit in dollar value per year associated with a reduction in the severe crash could pay as much as $\$ 700,000$. Overall, the outcome of this objective showed that the sensor data-based assessment could also be used as a useful and practical approach for evaluating other speed management strategies. In addition, the developed drivers' speed change behavior models could be easily applied to other arterials and locations as long as the models are well-calibrated.

- Understand the role of conventional speed management strategies in supporting connected arterials.

With the accelerated development of wireless technology, connected vehicle (CV) is believed to be one of the promising technological advances for the automotive revolution. To shed more light on the role of conventional speed management strategies on connected corridors, the impacts of signal retiming, and coordination, on transit signal priority (TSP) was evaluated on a connected corridor in Salt Lake City, UT. Results indicated that the ratio of TSP served is $33.12 \%$ before signal retiming, which is lower than that of $35.29 \%$ after signal retiming. As a result, the bus reliability for the 
northbound and southbound of the corridor improved by $2.65 \%$ and $1.21 \%$, respectively, after signal retiming. In addition, bus travel time and bus running time reduced after signal retiming, which resulted in improved bus speed after signal timing. All those measurements indicate that the speed management strategy implemented along this CV corridor results in an improvement of TSP.

- Examine the possibility of using controller event-based data to estimate multimodal signal performance measures.

To examine the possibility of using controller event-based data to estimate multimodal signal performance measures on four major signalized intersections on Ina Rd., Arizona, were selected as case study locations. The results of estimating the pedestrian delay using the calibrated model at each intersection showed the proposed method was able to capture and track the actual delay fluctuation during the day with an average of $10 \%$ of mean absolute error. Further, the result of the test of disaggregated prediction showed that the proposed method was transferable to other intersections with similar specifications. The application of the proposed method could be beneficial to the transportation agencies to estimate pedestrian delay in a more reliable, robust, and accurate approach for estimating pedestrian delay at signalized intersections where sensors are not available to collect pedestrian delay.

\subsection{LIMITATION AND RECOMMENDATION}

This section will describe the limitation and the recommendation for each chapter of this report separately.

For Chapter 2, the impact of speed management strategies on conventional roadways, one potential future work would be increasing the number of samples by expanding the coverage of the traffic sensors and extending the data collection period. Larger sample sizes are always helpful in making data-driven decisions more statistically robust. Another possible future work would be verifying the safety benefit using years of crash data collected after implementing SFS. Future studies should focus more on the impact of other speed management strategies on corridor mobility. Signal retiming and green waves could improve progression on coordinated arterials in addition to reducing average speed, 85th percentage speed, and the percentage of vehicles exceeding the speed limit.

The following recommendations are provided for further improving arterial safety, improving the effectiveness of the current speed management strategies implemented in the county, and optimizing the county's resources.

5- When dealing with speeding issues, generally three Es have included: Engineering, Enforcement, and Education. It is recommended that transportation agencies spend more resources on the Education element for enhancing public awareness on speeding issues. 
6- During the study, the research team found out that some of the newer generations of the SFS are able to collect the vehicle's speed. It is recommended that transportation agencies exchange the current traditional SFS for the newer generation.

7- Currently, large-scale third-party probe-based data is available to all local and state DOTs. Future research could focus on using real-time and historical thirdparty probe-based data to identify the locations prone to speeding.

Transportation agencies could benefit significantly from this type of information to relocate the law enforcement resources and optimally use all their available capacity.

For Chapter 3, due to the data limitation, the impact of speed management strategies on the connected corridor is only evaluated on transits. Future studies could focus on the impacts of those strategies on other modes of transportation. Moreover, to balance the benefits that served TSP to buses and the potential negative impact on other traffic, more studies need to be conducted to determine the potential of strategies in the future. Finally, note that the impacts of speed management strategies are subject to many aspects. Therefore, to explore the maximum potential of the speed management strategies, studies of changing other conditions may need to be conducted.

Lastly, for Chapter 4, using high-resolution traffic data for multimodal mobility evaluation, due to the data limitation, only cycle length, pedestrian effective green duration, and traffic flow were used as variables in the pedestrian delay function based on data available from the sensors. While the limitations discussed here should not have a significant impact on the results of this study, additional research should be conducted to extend the study findings. More studies would be needed to comprehensively evaluate if the proposed model could be transferred to other jurisdictions and counties. In addition, other variables could be considered as the potential variables for estimating pedestrian delay. Using the proposed method, system operators can easily determine the proportion of time when pedestrians experience delays larger than a predefined threshold. For example, pedestrians crossing the major street at the intersection of W Ina Rd. \& N Camino De La Tierra experience delays greater than 30 and 50 seconds, $70 \%$ and $51 \%$ of the time respectively. Similarly, at W Ina Rd. \& N Shannon Rd., W Ina Rd. \& N La Cholla Blvd., and W Ina Rd. \& N La Cañada Dr., pedestrians experience delays greater than 30 seconds, $73 \%, 85 \%$, and $86 \%$ of the time respectively. The high proportions of pedestrians experiencing delays greater than existing thresholds defined in the literature indicate that these intersections may be prone to higher risk-taking behaviors. It is recommended that related transportation agencies re-evaluate and revise their current signal timing, more specifically adding a separate phase for pedestrians. 


\subsection{REFERENCES}

Aarts, L., \& Van Schagen, I. (2006). Driving speed and the risk of road crashes: A review. Accident Analysis \& Prevention, 38(2), 215-224.

Ardeshiri, A., \& Jeihani, M. (2014). A speed limit compliance model for dynamic speed display sign. Journal of safety research, 51, 33-40.

Ariannezhad, A., Karimpour, A., Qin, X., Wu, Y.-J., \& Salmani, Y. (2021). Handling Imbalanced Data for Real-Time Crash Prediction: Application of Boosting and Sampling Techniques. Journal of Transportation Engineering, Part A: Systems, 147(3), 04020165.

Ariannezhad, A., Karimpour, A., \& Wu, Y.-J. (2020). Incorporating mode choices into safety analysis at the macroscopic level. Journal of Transportation Engineering, Part A: Systems, 146(4), 04020022.

Ariannezhad, A., \& Wu, Y.-J. (2019). Effects of heavy rainfall in different light conditions on crash severity during Arizona's monsoon season. Journal of Transportation Safety \& Security, 11(6), 579-594.

Ariannezhad, A., \& Wu, Y.-J. (2020). Large-scale loop detector troubleshooting using clustering and association rule mining. Journal of Transportation Engineering, Part A: Systems, 146(7), 04020064.

Bagdade, J., Nabors, D., McGee, H., Miller, R., \& Retting, R. (2012). Speed Management: A Manual for Local Rural Road Owners

Benavoli, A., Corani, G., \& Mangili, F. (2016). Should we really use post-hoc tests based on mean-ranks? The Journal of Machine Learning Research, 17(1), 152161. 
Blincoe, L., Miller, T. R., Zaloshnja, E., \& Lawrence, B. A. (2015). The economic and societal impact of motor vehicle crashes, 2010 (Revised)

Champness, P. G., Sheehan, M. C., \& Folkman, L.-M. (2005). Time and distance halo effects of an overtly deployed mobile speed camera.

Chilukuri, V., \& Virkler, M. R. (2005). Validation of HCM pedestrian delay model for interrupted facilities. Journal of transportation engineering, 131(12), 939-945.

Cruzado, I., \& Donnell, E. T. (2009). Evaluating effectiveness of dynamic speed display signs in transition zones of two-lane, rural highways in Pennsylvania. Transportation research record, 2122(1), 1-8.

Day, C. M., Bullock, D. M., Li, H., Lavrenz, S. M., Smith, W. B., \& Sturdevant, J. R. (2016). Integrating Traffic Signal Performance Measures into Agency Business Processes.

Day, C. M., Bullock, D. M., Li, H., Remias, S. M., Hainen, A. M., Freije, R. S., Stevens, A. L., Sturdevant, J. R., \& Brennan, T. M. (2014). Performance measures for traffic signal systems: An outcome-oriented approach (No. 162260296X)

Day, C. M., Li, H., Sturdevant, J. R., \& Bullock, D. M. (2018). Data-Driven Ranking of Coordinated Traffic Signal Systems for Maintenance and Retiming. Transportation research record, 2672(18), 167-178.

Day, C. M., Smaglik, E. J., Bullock, D. M., \& Sturdevant, J. R. (2008). Real-time arterial traffic signal performance measures.

Day, C. M., Taylor, M., Mackey, J., Clayton, R., Patel, S. K., Xie, G., Li, H., Sturdevant, J. R., \& Bullock, D. M. (2016). Implementation of automated traffic signal performance measures. Institute of Transportation Engineers (ITE), 86(8).

De Pauw, E., Daniels, S., Brijs, T., Hermans, E., \& Wets, G. (2014a). Automated section speed control on motorways: An evaluation of the effect on driving speed. Accident Analysis \& Prevention, 73, 313-322. 
De Pauw, E., Daniels, S., Brijs, T., Hermans, E., \& Wets, G. (2014b). Behavioural effects of fixed speed cameras on motorways: Overall improved speed compliance or kangaroo jumps? Accident Analysis \& Prevention, 73, 132-140.

Draft, S. (2006). J2735 dedicated short range communications (dsrc) message set dictionary. Rev 0.7, Jam.

Dunn, R., \& Pretty, R. (1984). Mid-block pedestrian crossings-an examination of delay. Australian Road Research, 12(4).

Elefteriadou, L. A. (2016). The highway capacity manual 6th edition: A guide for multimodal mobility analysis. ITE Journal, 86(4).

FHWA. (2020). Arterial Management Program https://ops.fhwa.dot.gov/arterial_mgmt/

Fi, I., \& Igazvölgyi, Z. K. (2014). Travel time delay at pedestrian crossings based on microsimulations. Periodica Polytechnica Civil Engineering, 58(1), 47-53.

Fox, J. (2015). Applied regression analysis and generalized linear models. Sage Publications.

Friedman, M. (1937). The use of ranks to avoid the assumption of normality implicit in the analysis of variance. Journal of the american statistical association, 32(200), 675-701.

Gehlert, T., Schulze, C., \& Schlag, B. (2012). Evaluation of different types of dynamic speed display signs. Transportation research part F: traffic psychology and behaviour, 15(6), 667-675.

Hallmark, S. L., Qiu, Y., Hawkins, N., \& Smadi, O. (2015). Crash modification factors for dynamic speed feedback signs on rural curves. Journal of Transportation Technologies, 5(01), 9.

Hassani, A., Joerger, M., Arana, G. D., \& Spenko, M. (2018). Lidar data association risk reduction, using tight integration with INS. (Ed.), ${ }^{\wedge}($ Eds.). Proceedings of the 31st 
International Technical Meeting of The Satellite Division of the Institute of Navigation (ION GNSS+ 2018).

Hassani, A., Morris, N., Spenko, M., \& Joerger, M. (2019). Experimental integrity evaluation of tightly-integrated IMU/LiDAR including return-light intensity data. (Ed.), ${ }^{\wedge}$ (Eds.). Proceedings of the 32nd International Technical Meeting of The Satellite Division of the Institute of Navigation (ION GNSS+ 2019).

HCM. (2010). Transportation Research Board of the National Academies, Washington, DC, 2010. Google Scholar.

Hernandez, S. (2017). Estimation of average payloads from weigh-in-motion data. Transportation research record, 2644(1), 39-47.

Hernandez, S., \& Hyun, K. (2020). Fusion of weigh-in-motion and global positioning system data to estimate truck weight distributions at traffic count sites. Journal of Intelligent Transportation Systems, 24(2), 201-215.

Hirotugu, A. (1974). A new look at the statistical model identification. IEEE Transactions on Automatic Control, 19(6), 716-723.

Huang, T., Poddar, S., Aguilar, C., Sharma, A., Smaglik, E., Kothuri, S., \& Koonce, P. (2018). Building Intelligence in Automated Traffic Signal Performance Measures with Advanced Data Analytics. Transportation research record, 2672(18), 154166.

Hubbard, S. M., Bullock, D. M., \& Day, C. M. (2008). Integration of real-time pedestrian performance measures into existing infrastructure of traffic signal system. Transportation research record, 2080(1), 37-47.

Imprialou, M.-I. M., Quddus, M., Pitfield, D. E., \& Lord, D. (2016). Re-visiting crashspeed relationships: A new perspective in crash modelling. Accident Analysis \& Prevention, 86, 173-185.

Joerger, M., \& Hassani, A. (2020). A New Data Association Method Using Kalman Filter Innovation Vector Projections. (Ed.), ${ }^{\wedge}($ Eds.). 2020 IEEE/ION Position, Location and Navigation Symposium (PLANS). 
Karimpour, A., Anderson, J. C., Kothuri, S., \& Wu, Y.-J. (2021). Estimating pedestrian delay at signalized intersections using high-resolution event-based data: a finite mixture modeling method. Journal of Intelligent Transportation Systems, 1-18.

Karimpour, A., Ariannezhad, A., \& Wu, Y.-J. (2019). Hybrid data-driven approach for truck travel time imputation. IET Intelligent Transport Systems, 13(10), 15181524.

Karimpour, A., Kluger, R., Liu, C., \& Wu, Y.-J. (2021). Effects of speed feedback signs and law enforcement on driver speed. Transportation research part F: traffic psychology and behaviour, 77, 55-72.

Karimpour, A., Kothuri, S., Anderson, J., \& Wu, Y.-J. (2020). Estimating Pedestrian Delay at Signalized Intersections Using Finite Mixture Modeling. Transportation Research Board 100th Annual MeetingTransportation Research Board

Karimpour, A., \& Wu, Y.-J. (2021). Freeway to Arterial Interfaces. In Elsevier (Ed.), International Encyclopedia of Transportation (pp. 162-168). https://doi.org/10.1016/B978-0-08-102671-7.10326-4

Kockelman, K., Bottom, J., Kweon, Y., Ma, J., \& Wang, X. (2006). Safety impacts and other implications of raised speed limits on high-speed roads (Vol. 90). Transportation Research Board Washington, DC, USA.

Kockelman, K. M., \& Ma, J. (2007). Freeway speeds and speed variations preceding crashes, within and across lanes. (Ed.), ${ }^{\wedge}($ Eds.). Journal of the Transportation Research Forum.

Kothuri, S. M., Reynolds, T., Monsere, C. M., \& Koonce, P. (2012). Preliminary Development of Methods to Automatically Gather Bicycle Counts and Pedestrian Delay at Signalized Intersections. (Ed.), ${ }^{\wedge}$ (Eds.). 91st Annual Meeting of the Transportation Research Board, Washington, DC.

Lao, Y., Zhang, G., Corey, J., \& Wang, Y. (2012). Gaussian mixture model-based speed estimation and vehicle classification using single-loop measurements. Journal of Intelligent Transportation Systems, 16(4), 184-196. 
Lee, C., Lee, S., Choi, B., \& Oh, Y. (2006). Effectiveness of speed-monitoring displays in speed reduction in school zones. Transportation research record, 1973(1), 2735.

Leonard, B. D., Mackey, J., Sheffield, M., Bassett, D., Larson, S., \& Hooper, I. J. T. R. R. (2019). Demonstrating Transit Schedule Benefits with a Dedicated ShortRange Communication-Based Connected Vehicle System. 2673(12), 215-224.

Li, Q., Wang, Z., Yang, J., \& Wang, J. (2005). Pedestrian delay estimation at signalized intersections in developing cities. Transportation Research Part A: Policy and Practice, 39(1), 61-73.

Ma, X., Karimpour, A., \& Wu, Y.-J. (2020). Statistical evaluation of data requirement for ramp metering performance assessment. Transportation Research Part A: Policy and Practice, 141, 248-261.

Malyshkina, N. V., \& Mannering, F. (2008). Effect of increases in speed limits on severities of injuries in accidents. Transportation research record, 2083(1), 122127.

Mansourkhaki, A., Karimpour, A., \& Sadoghi Yazdi, H. (2017). Non-stationary concept of accident prediction. (Ed.), ${ }^{\wedge}(E d s$.$) . Proceedings of the Institution of Civil$ Engineers-Transport.

Mansourkhaki, A., Karimpour, A., \& Yazdi, H. S. (2017). Introducing prior knowledge for a hybrid accident prediction model. KSCE Journal of Civil Engineering, 21(5), 1912-1918.

MioVision Team. (2019). MioVision's TrafficLink platform https://miovision.com/trafficlink/

Mousavi, S. M., Osman, O. A., Lord, D., Dixon, K. K., \& Dadashova, B. (2021). Investigating the safety and operational benefits of mixed traffic environments with different automated vehicle market penetration rates in the proximity of a driveway on an urban arterial. Accident Analysis \& Prevention, 152, 105982.

NHTSA. (2014). Speed Management Strategic Initiative. 
NHTSA. (2018). 2018 fatal motor vehicle crashes: overview (No. DOT HS 812 826)

NHTSA. (2006). Uniform Guidelines for State Highways Safety Programs: Highway Safety Program Guideline No. 3.

Pearson, K. (1895). VII. Note on regression and inheritance in the case of two parents. proceedings of the royal society of London, 58(347-352), 240-242.

Pereira, D. G., Afonso, A., \& Medeiros, F. M. (2015). Overview of Friedman's test and post-hoc analysis. Communications in Statistics-Simulation and Computation, 44(10), 2636-2653.

Pour-Rouholamin, M., \& Zhou, H. (2016). Investigating the risk factors associated with pedestrian injury severity in Illinois. Journal of safety research, 57, 9-17.

Qiao, F., Yi, P., Yang, H., \& Devarakonda, S. (2002). Fuzzy logic based intersection delay estimation. Mathematical and computer modelling, 36(11-13), 1425-1434.

Ragnøy, A. (2011). Automatic section speed control: Evaluation Results.

Regehr, J. D., Maranchuk, K., Vanderwees, J., \& Hernandez, S. (2020). Gaussian Mixture Model to Characterize Payload Distributions for Predominant Truck Configurations and Body Types. Journal of Transportation Engineering, Part B: Pavements, 146(2), 04020017.

Remias, S. M., Day, C. M., Waddell, J. M., Kirsch, J. N., \& Trepanier, T. (2018). Evaluating the Performance of Coordinated Signal Timing: Comparison of Common Data Types with Automated Vehicle Location Data. Transportation research record, 2672(18), 128-142. https://doi.org/10.1177/0361198118794546.

Rune, E., \& Vaa, T. (2009). The handbook of road safety measures. Emerald.

Santiago-Chaparro, K. R., Chitturi, M., Bill, A., \& Noyce, D. A. (2012). Spatial effectiveness of speed feedback signs. Transportation research record, 2281(1), 8-15. 
Siegal, S. (1956). Nonparametric statistics for the behavioral sciences. McGraw-hill.

Stone, M. (1979). Comments on model selection criteria of Akaike and Schwarz. Journal of the Royal Statistical Society. Series B (Methodological), 276-278.

TTI. (2019). 2019 Annual Urban Mobility Report.

(https://static.tti.tamu.edu/tti.tamu.edu/documents/mobility-report-2019.pdf)

Ullman, G. L., \& Rose, E. R. (2005). Evaluation of dynamic speed display signs.

Transportation research record, 1918(1), 92-97.

Urbanik, T., Tanaka, A., Lozner, B., Lindstrom, E., Lee, K., Quayle, S., Beaird, S., Tsoi, S., Ryus, P., \& Gettman, D. (2015). Signal Timing Manual. Transportation Research Board Washington, DC.

Vincent, W. J., \& Weir, J. P. (1999). Statistics in kinesiology (Vol. 142). Human Kinetics Champaign, IL.

Virkler, M. R. (1998). Pedestrian compliance effects on signal delay. Transportation research record, 1636(1), 88-91.

Wang, Q., Yang, X., Leonard, B. D., \& Mackey, J. (2020). Field evaluation of connected vehicle-based transit signal priority control under two different signal plans. Transportation research record, 2674(7), 172-180.

Wang, X., \& Tian, Z. (2010). Pedestrian delay at signalized intersections with a twostage crossing design. Transportation research record, 2173(1), 133-138.

Wang, X., Zhou, Q., Quddus, M., \& Fan, T. (2018). Speed, speed variation and crash relationships for urban arterials. Accident Analysis \& Prevention, 113, 236-243.

Wei, D., Liu, H., \& Tian, Z. (2015). Vehicle delay estimation at unsignalised pedestrian crosswalks with probabilistic yielding behaviour. Transportmetrica A: transport science, 11(2), 103-118. 
West, B. T., Welch, K. B., \& Galecki, A. T. (2014). Linear mixed models: a practical guide using statistical software. Chapman and Hall/CRC.

WHO. (2020). Road traffic injuries.

Wissler, C. (1905). The Spearman correlation formula. Science, 22(558), 309-311.

Yang, Q., Wu, G., Boriboonsomsin, K., \& Barth, M. (2018). A novel arterial travel time distribution estimation model and its application to energy/emissions estimation. Journal of Intelligent Transportation Systems, 22(4), 325-337.

Yang, S., \& Cooke, P. (2018). How accurate is your travel time reliability?-Measuring accuracy using bootstrapping and lognormal mixture models. Journal of Intelligent Transportation Systems, 22(6), 463-477.

Zheng, Y., \& Elefteriadou, L. (2017). A model of pedestrian delay at unsignalized intersections in urban networks. Transportation research part B: methodological, $100,138-155$.

Zimmerman, D. W., \& Zumbo, B. D. (1993). Relative power of the Wilcoxon test, the Friedman test, and repeated-measures ANOVA on ranks. The Journal of Experimental Education, 62(1), 75-86. 